Journal of Educational

and Psychological Sciences

Volume (5), Issue (36): 30 Sep 2021

P: 162 - 180
AJSRP

ISSN: 2522-3399
مجلة العلوم

التربوية والنفسية

المجلد (5)، العدد (36): 30 سبتمبر 2021 م

ص: 162 - 180

\title{
The effectiveness of a counseling program It is based on positive interventions in reducing emotional divorce among the workless spouses in the light of the prevalence of corona virus
}

\author{
Marwan Musaad Abu Samhadana \\ Queen Rania Center for Psychological Counseling || Mutah University || Jordan
}

\begin{abstract}
The current study aimed to reveal the effectiveness of a counseling program based on positive psychology in reducing emotional divorce among a sample of the unemployed during the Corona virus, and to achieve the objectives of the study, a random sample was chosen available from unemployed parents with a medium or high level of emotional divorce. Where the study sample consisted of (18) fathers and they were divided into two groups: an experimental group, in which the number of fathers was (9) fathers who underwent the current study, and a control group in which the number of fathers was (9) fathers who did not undergo any therapeutic intervention, and a measure of emotional divorce was developed. And the preparation of a counseling program based on positive psychology, and after applying the counseling program to the members of the experimental group for a month, the results of the study concluded that the experimental group had a lower level of emotional divorce compared with the control group, and it was also found that the members of the experimental group retained the effect of the program after a month From the end of the program, the study came out with some recommendations, including: Attempting to implement the extension program on other categories of the unemployed through the Family Protection Centers and the counselors.
\end{abstract}

Keywords: positive psychology, emotional divorce, unemployed, counseling program.

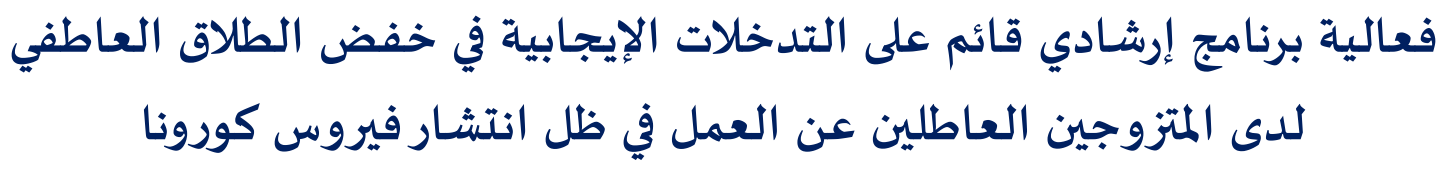

مروان مسعد أبو سمهدانه

مركز الملكة رانيا للاستشارات النفسية || جامعة مؤتة || الأردن

\begin{abstract}
المستخلص: هدفت الدراسة الحالية للكشف عن فعالية برنامج إرشادي مستند إلى التدخلات الإيجابية في خفض الطلاق العاطفي لدى

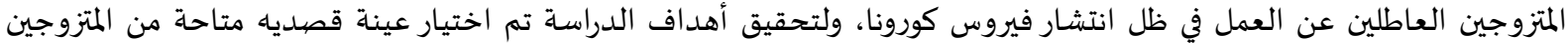

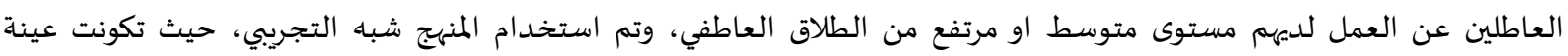

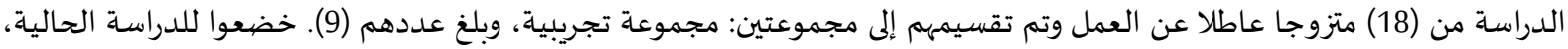

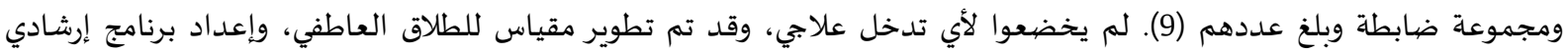

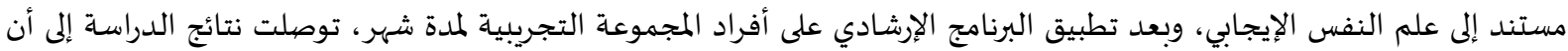

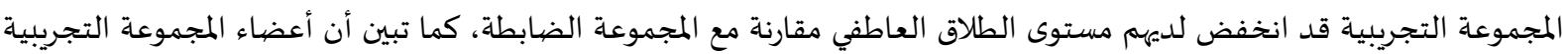

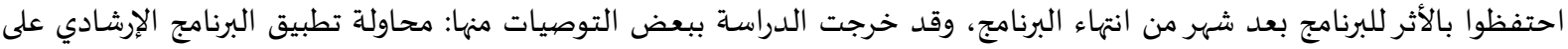
فئات أخرى من العاطلين عن العمل من خلال مراكز حماية الأسرة والمرشدين.
\end{abstract}


يتجاوز علم النفس الإيجابي بتجاوز الدعوة إلى السعادة والتفاؤل وحب الحياة، إنه يسعى إلى تقديم بديل أفضل لما سبق من سيكولوجية المرض، ويمكن أن يساعد علم النفس الإيجابي خصوصا مع التطورات الحالية في المجتمع ككل والاسرة بشكل خاص، حيث تغيرت الأسر وأصبحت تميل إلى بعض السضدونس السلوكيات غير المناسبة ومنها الطلاق العاطفي، الذي قد يزيد مع وجود ضغوط معينة كالبطالة التي زادت في الآونة الأخيرة.

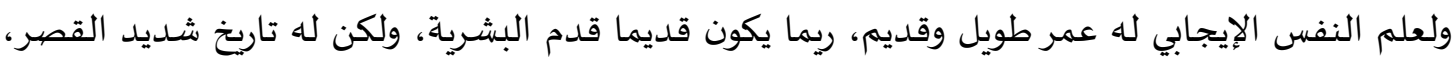

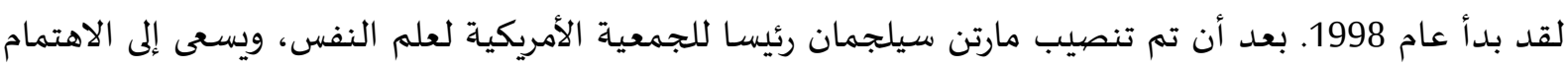

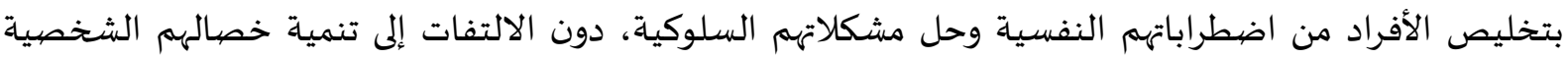
الطيبة ومهاراتهم الإيجابية وتطويرها (الصبوة، 2008). ومنذ ظهور هذا العلم في عام 1998 على يد مارتن سليجمان M. Seligman وزميله ميهالي سكيزينتميهالي Mihali Csikszentmihalyi العلم وأساليبه العلمية التطبيقية التي نتجت عن إطاره النظري، في الوقاية ضد الإصابة بالأمراض الجسمية

والاضطرابات النفسية، وفي تخليصها من المعاناة منها أو التخفيف من حدتها (الصببوة، 2010).

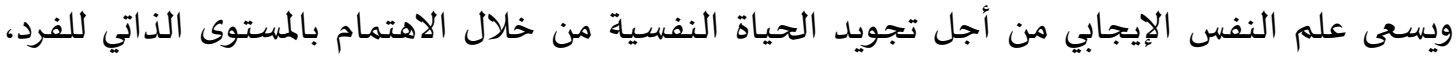

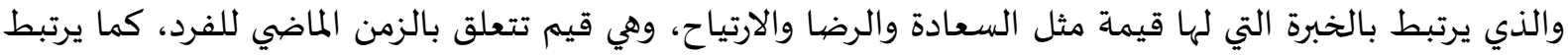

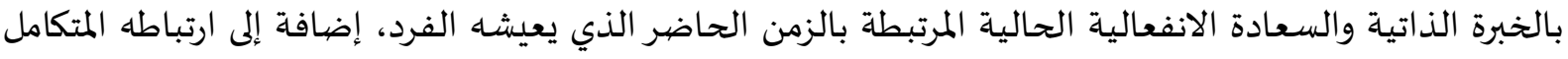

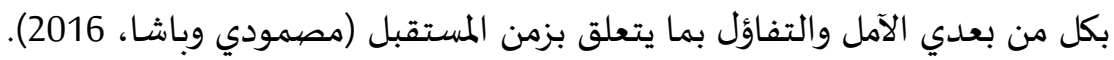

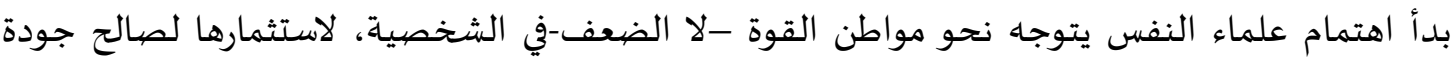

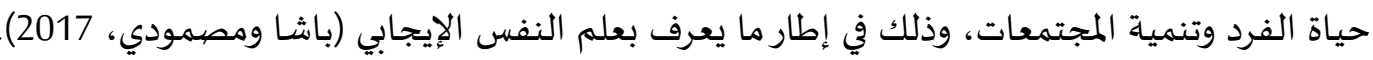

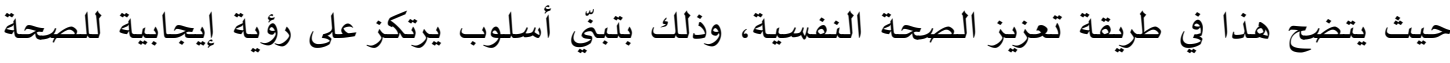

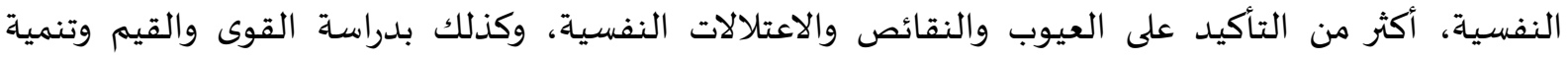

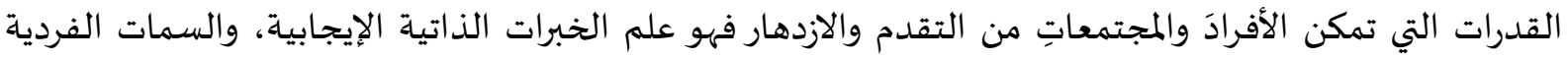

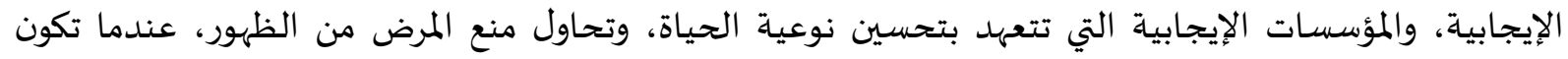
الحياة فارغة وبلا معنى (شريفي، 2016).

وتعرف البطالة بأنها حالة عدم وجود عمل لطالبه رغم الرغبالة فيلة فيه والبحث عنه أي وجود مجموعة

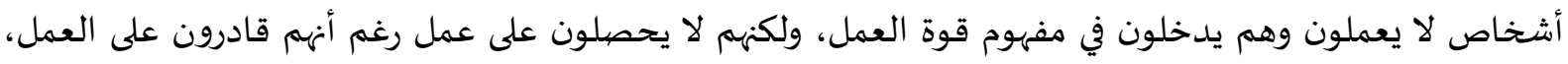
وراغبون به وبالتالي هم متعطلون عن ممارسة العمل (رفاعي، 2013).

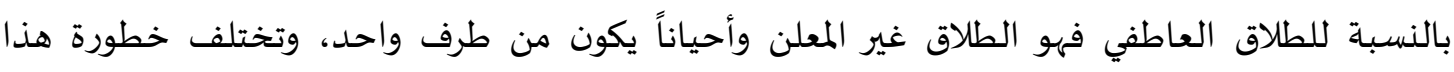

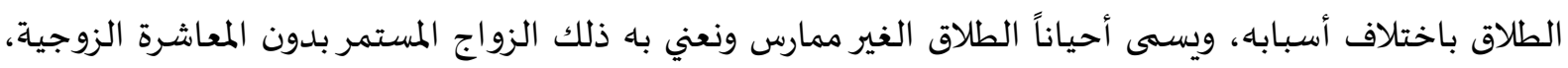

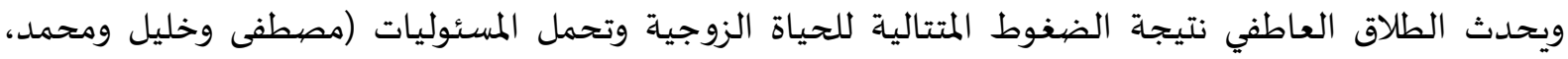

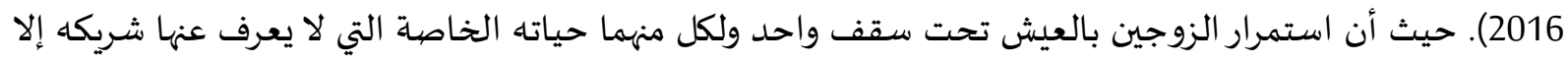

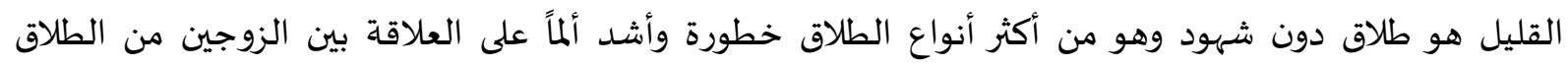
الشرعي (الحسين، 2013). 
ويعد الطلاق العاطفي واحدا من أهم جوانب التوتر في العلاقة ونوعيتها بين الأزواج، وقد يكون الانفصال

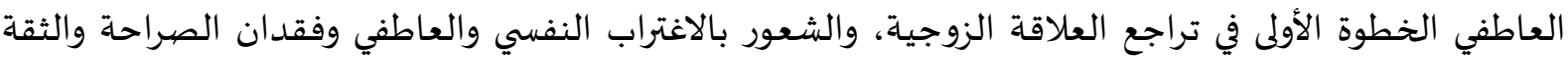
المتبادلة بين الزوجين (Hijazi، 2000) وتتميز ظاهرة الطلاق العاطفي التي تنشأ بين الزوجين بمجموعة سمات تعتبر مؤشراً لبروز هذه الظاهرة بينهما بشكل واضح، ومن أهم تلك السمات، هي وجود انفصال مادي واضح بين الزوجين، وعدم وجود رغبة في

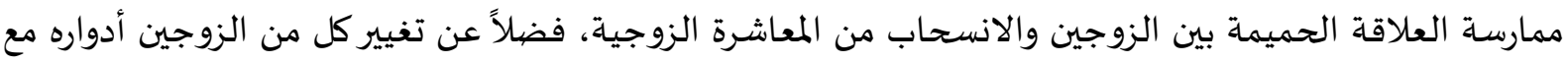

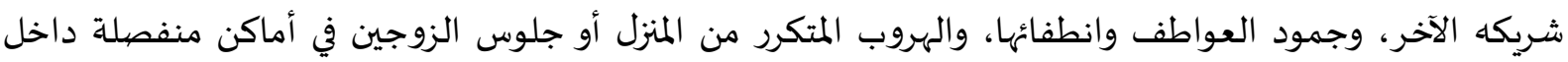
البيت (الفتلاوي وجبار، 2012).

هناك مظاهر للطلاق العاطفي منها: يقلل كل طرف من شأن الآخر (أفكاره، مشاعره، تصرفاته أو

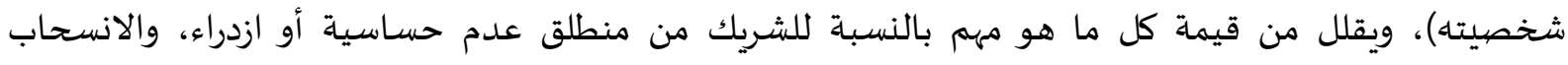

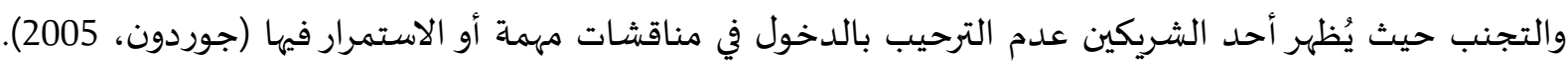

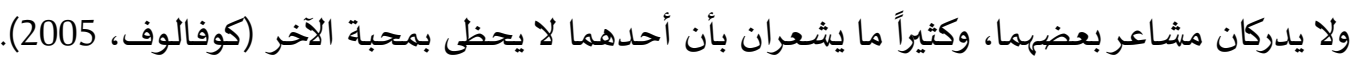

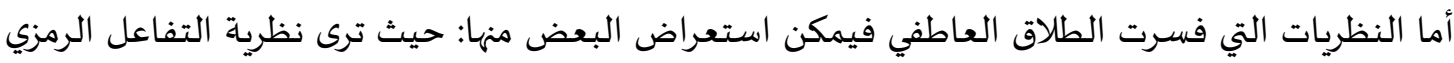

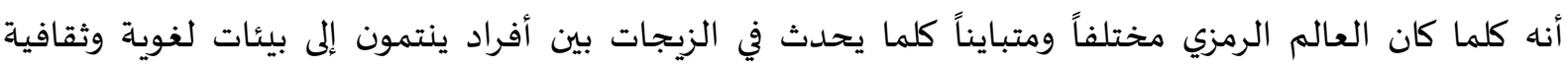

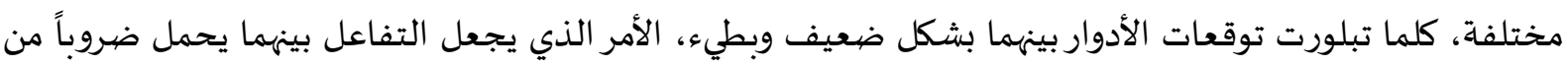

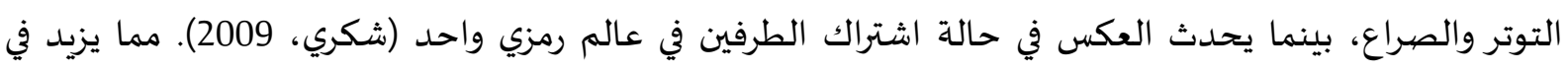

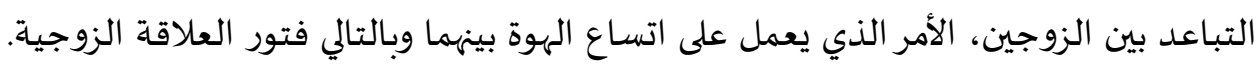

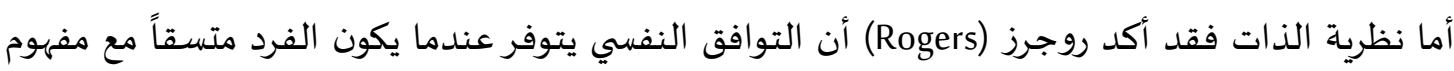

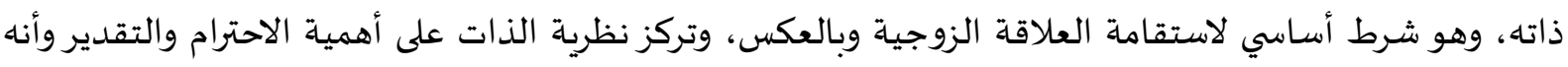

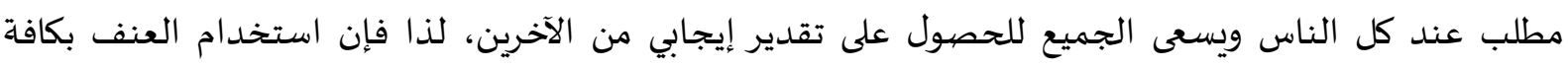
اشكاله، يؤدي إلى قلة وانعدام الاحترام بين الزوجين، مما ينتج عنه ضعف العبع العلاقة العاطفية بينهما (بادوبلان،

وترى نظرية أريكسون في النمو النفسي الاجتماعي في الزواج الناجح بأن الألفة تجعل الزواج ذو المعنى، ذلك

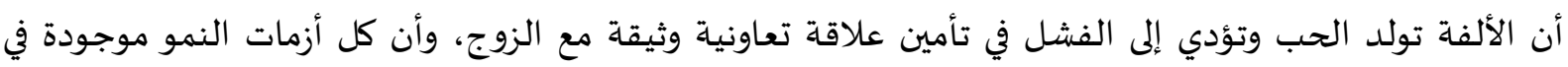

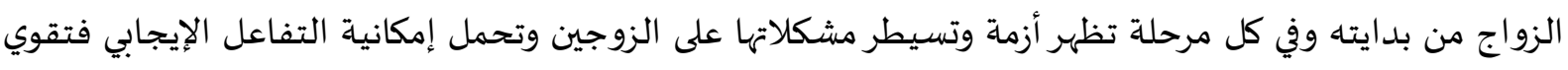

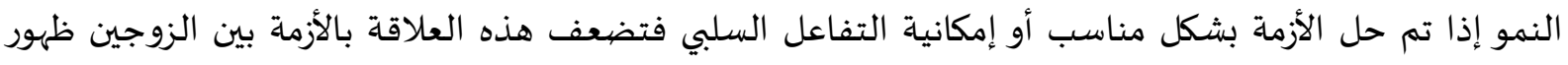

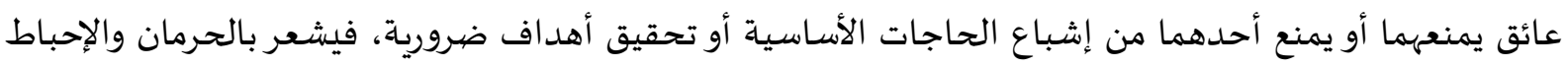

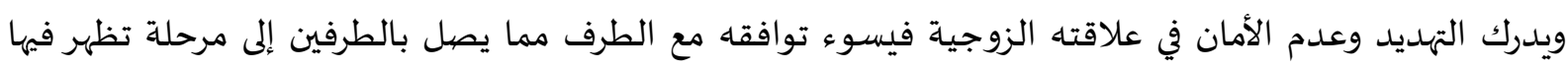
مظاهر الانفصال العاطفي (الين، 2010). بينما ترى نظرية التفكير اللاعقلاني أن هناك إحدى عشرة فكرة لا عقلانية أو خاطئة يفترض بهان الأنها أنها

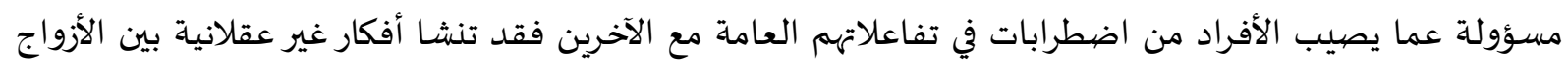

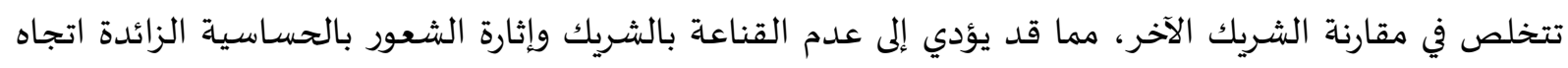

هذا الشريك كذلك الشعور بالحب المثالي بين الأزواج قد يؤدي إلى آثار سلبية في العلاقات الأسرية (Corey, 2013).

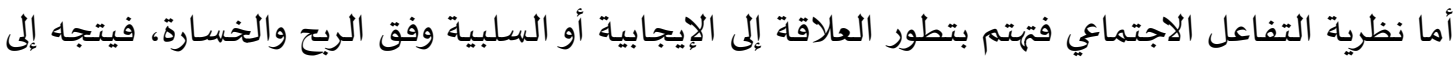

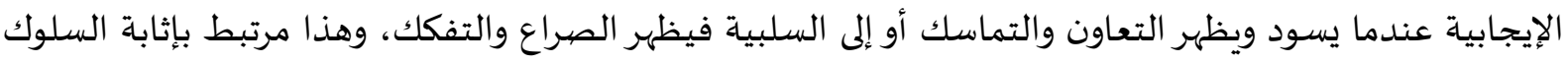


الذي يعمل على تقوية العلاقة، وعدم إثابته تضعفها وتطفئها لكنها اشترط في الثواب أن يكون ذا قيمة نفسية عند

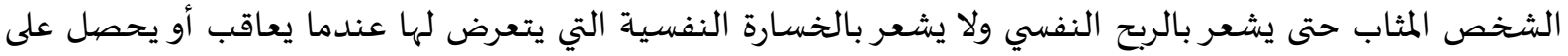
ثواب بسيط من التفاعل مع الآخرين (شكري، 2009).

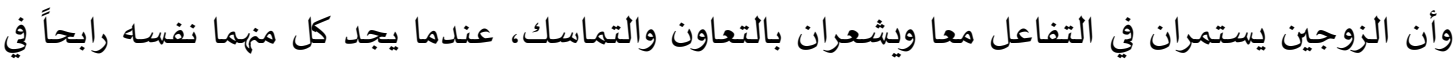

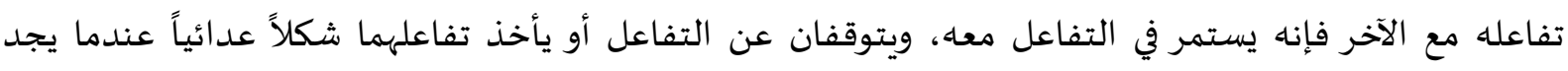

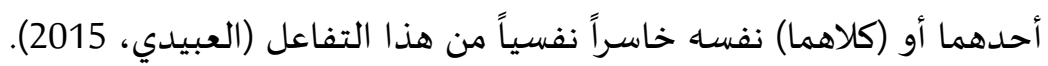

مشكلة البحث: نعيش في وقتنا الحالي أزمة عالمية وليست عربية أو محلية فقط لا أحد يدري ما نهايتها، أزمة قد تتجاوز

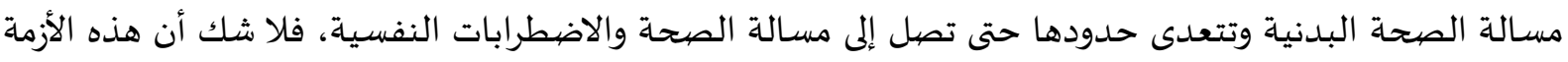

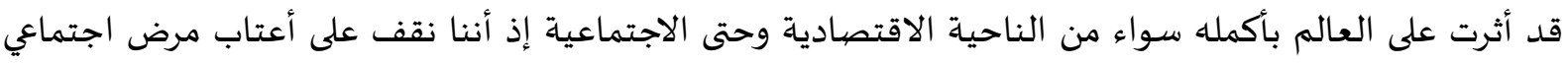
وليس وبائيا فقط. وتعد مترتبات مرض كورونا ذات مؤثرات مختلفة على كل المجتمع والتي حدثت في الوقت الحالي فهي تعتبر

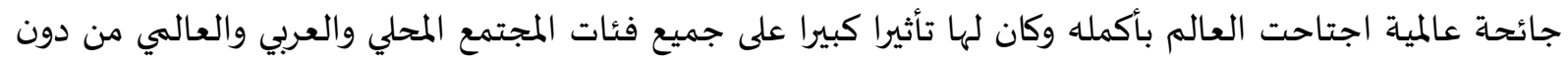

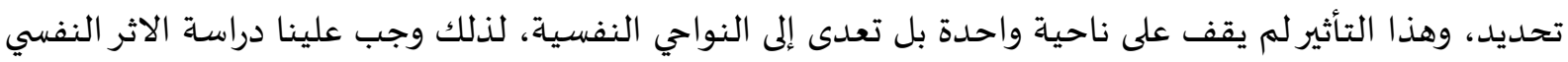

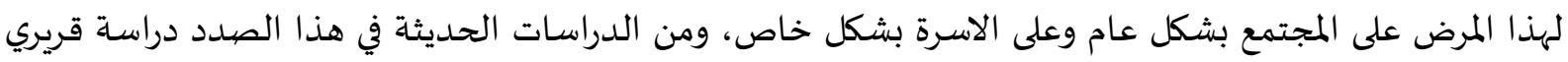

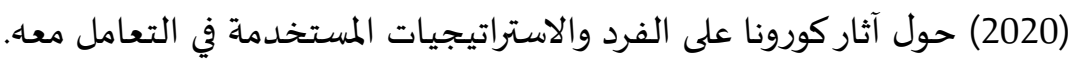

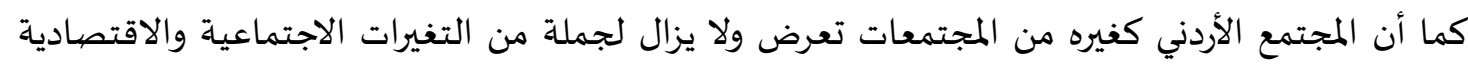
والنفسية والثقافية وحتى السياسية والامنية، والتي مست في المقام الاول خريطة الصحتة، حيت الميث تكمنت من من تغييرها

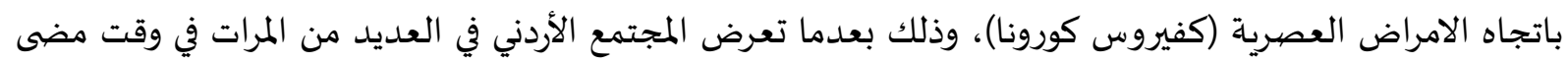

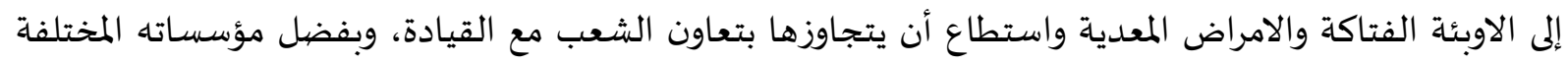
(فتيحةة، 2017)

لقد بلغ معدل انتشار البطالة في الأردن من حملة الشهادات الجامعية في الريع الأول من عام (2017) (14.6\%) حيث بلغ معدل الذكور (12.7\%) مقابل (23.7\%) للإناث، وبحسب التقرير السنوي الصادر عن عن دادئ دائرة

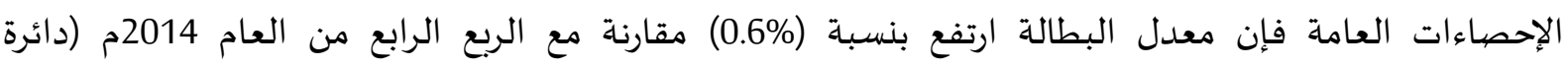

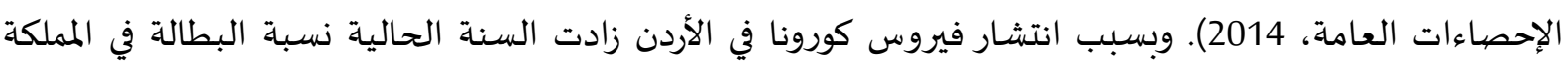

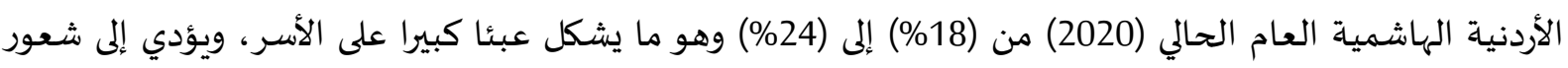

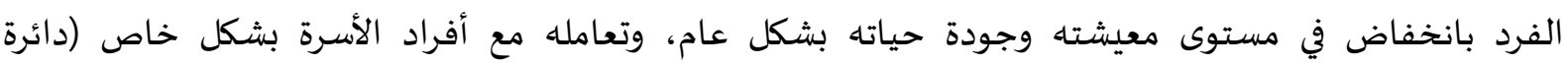
الإحصياءات العامة، 2020).

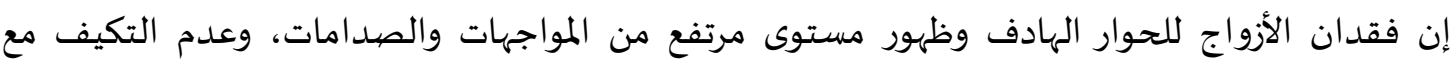

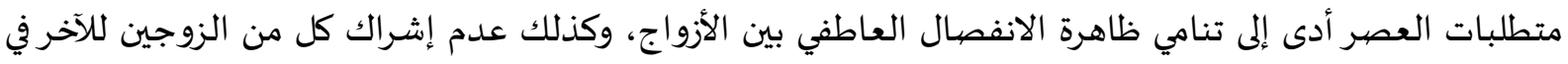

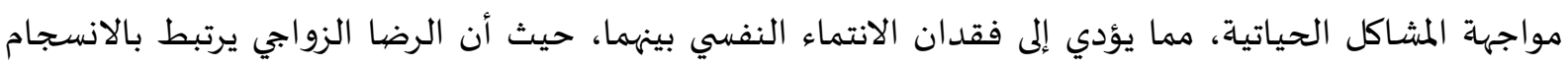

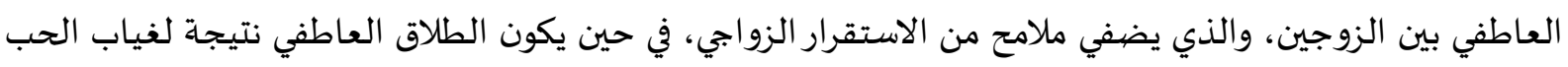

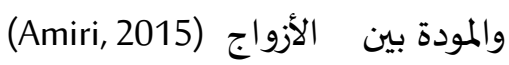


وحاولت دراسـة النجداوي (2018) بمحاولة فهم ظاهرة الطلاق العاطفي في المجتمع الأردني، باعتباره من بين المشكلات التي تواجه بعض الأسر الأردنية، وقد توصلت أن الطلاق العاطفي موجود في الأردن، ولا يمكن أنكاره، ولكن

$$
\text { من الصعب التعرف على أرقامه بدقة. }
$$

ومن خلال ملاحظات الباحث كونه يعمل لدى مركز الملكة رانيا العبد الله للاستشارات النفسية فقد تبين له من خلال مراجعة العديد من المتزوجين العاطلين عن العمل وجود مشكلات أسرية، وكانت تعزى إلى الطلاق العاطفي

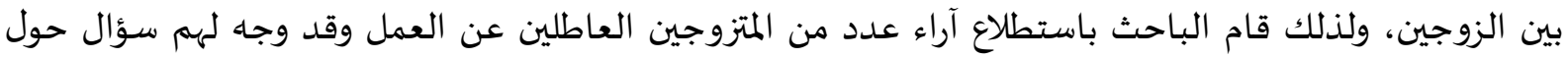

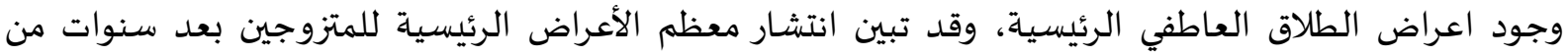
الزواج، ولذلك ارتأى الباحث القيام بهذا البحث الميداني، لمساعدة هذه الفئة من المراجعين للمركز.

أسئلة الدراسة:

بناء على ما سبق؛ تتحدد مشكلة البحث في السؤال الرئيسي التالي: هل هناك فعالية للبرنامج الإرشادي

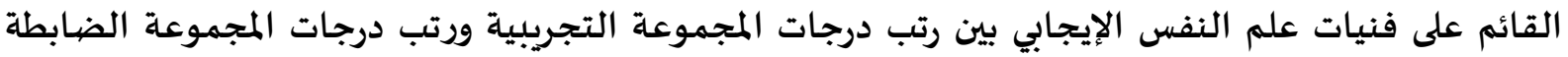
في خفض الطلاق العاطفي والاحتفاظ بمستوى الانخفاض لدى المتزوجين العاطلين عن العمل في فترة انتشار فيروس كورونا؟ ويتفرغ عن هذا السؤال ما يلي: 1. هل هناك فروق ذات دلالة إحصائية عند مستوى (م=0.05) بين رتب متوسطات المجموعة التجريبية ورتب

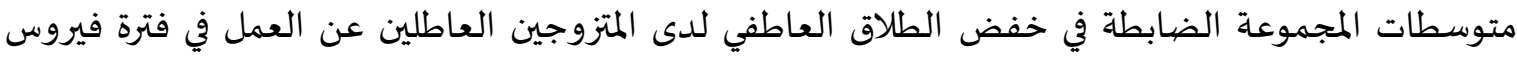
كورونا؟

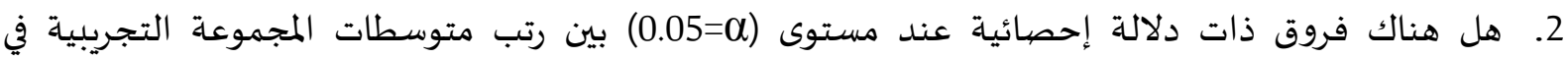

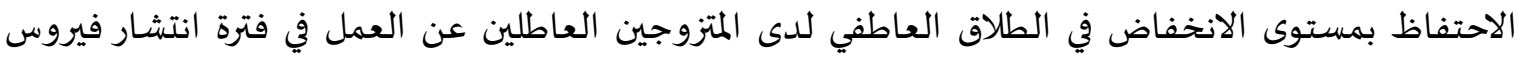

$$
\text { كورونا؟ }
$$

$$
\text { تكمن أهمية البحث في الآتي: }
$$

الأهمية النظرية:

- تنبثق أهمية الدراسة الحالية من تناولها متغير الطلاق العاطفي والذي يعد له قيمة إيجابية في التخفيف من

$$
\text { المشكلات الزوجية. }
$$

- تبرز أهمية الدراسة الحالية أيضا من أهمية استخدام متغيرات علم النفس الإيجابي كطريقة لمساعدة الأسرة

$$
\text { بشكل حديث. }
$$

- كما تستمد الدراسة أهميتها أيضاً من أهمية متغير اجراء برامج إرشادية المتزوجين العاطلين عن العمل المطلقين عاطفيا في ظل انتشار كورونا. - - متمثل أهمية الدراسة من أهمية الفئة التي يتناولها وهي فئة المتزوجين العاطلين عن العمل. الأهمية التطبيقية: - تنبثق الأهمية التطبيقية لهذه الدراسة من أهمية اعداد الباحث لمقياس الطلاق العاطفي كطريقة من طرق الكشف عن الظاهرة لدى المتزوجين العاطلين عن العمل. لاهيك. 
- يمكن الاستفادة من البرنامج الإرشادي في خفض الطلاق العاطفي لدى فئة تتعرض لكم كبير من الضغوط نتيجة فقدان فرصاة العمل. - يمكن أن يستفيد منها المرشدين الأسريين في مساعدة أولياء الأمور ذوي الوضع النفسي غير المستقر. حدود البحث:

يتم تعميم نتائج البحث الحالي في ضوء الحدود الآتية:

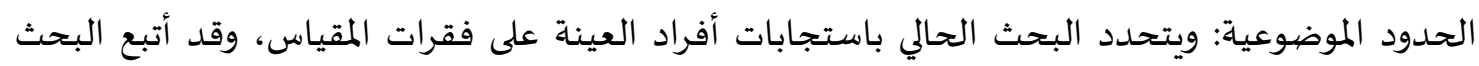

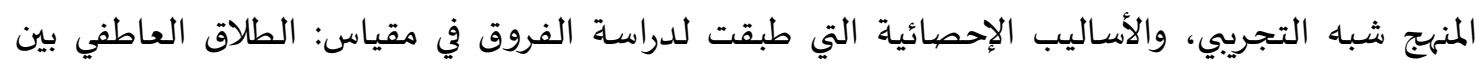
المجموعة التجريبية والضابطة. الحدود البشرية: المتزوجين المراجعين للمركز الذين لديهم مستوى متوسط أو مرتفع من الطلاق العاطفي

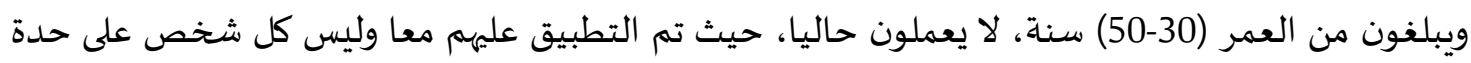

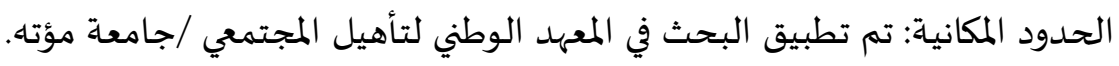
الحدود الزمانية: تم تطبيق البحث الحالي خلال عام2020 ، حيث المئي استغرق تطبيق البرنامج شهرا واحدا.

$$
\text { مصطلحات الدراسة: }
$$

- علم النفس الإيجابي: يمكن تعريف علم النفس الإيجابي، بأنه الدراسة الموضوعية للخصال الإيجابية في

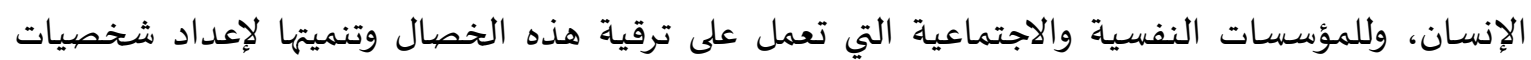

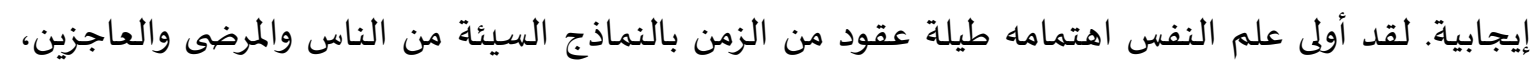

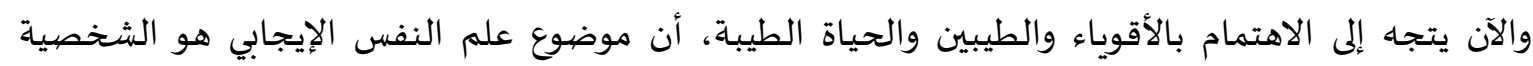
الطيبة الفاضلة القوية (معمرية، 2010). - مكونات علم النفس الإيجابي المرتبطة بجودة الحياة الذاتية والتي يستهدفها البرنامج العلاجي الحالي:

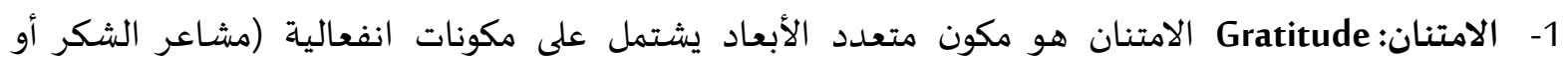

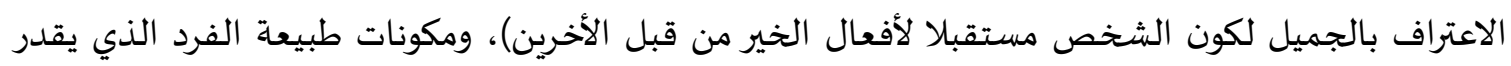

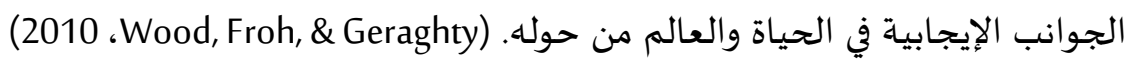
2- سمات القوة الشخصية:Character strengths تشير سمات القوة الشخصية إلى مكون من 24 سمة Park, Peterson, (إيجابية فردية (مثل فعل الخير، والتواضع) وهي مصنفة إلي ست فئات واسعة من الفضيائل \&eligman (Peterson \& Seligman, 2004) 3- أفعال الخير: Kindness تشير أفعال الخير إلي سمة شخصية ذات طبيعة متعددة الأبعاد، تتضمن ثلاث

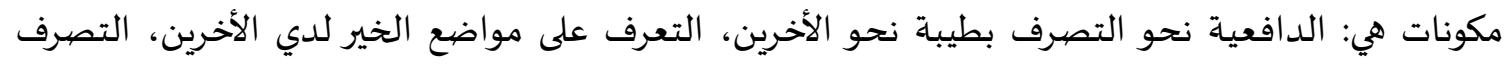

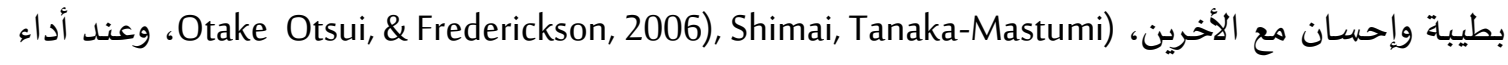

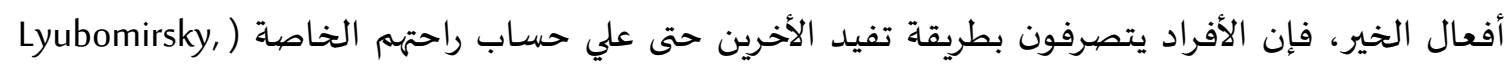
(2006 Sheldon, \& Schkade, 2005; Otake et al 
4- التفاؤل: Optimism يعرف التفاؤل على أنه كلا من توقع عام على سبيل المثال، الميل إلي توقع حدوث نتائج

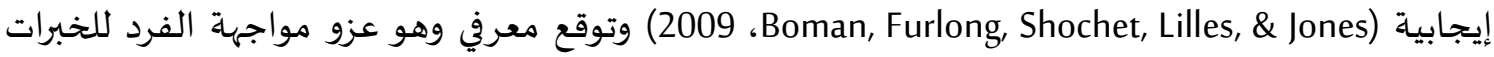
السلبية إلى عوامل خارجية مؤقتة ومحدودة، أما الخبرات الإيجابية فتعزي إلى عوامل دائمة شخصية متعلقة بالفرد (Seligman، 1991). 5- الأمل: Hope الأمل هو حالة دافعية إيجابية تتضمن كلا من مكون معرفي ومكون سلوكي، أما المكون المعرفي فيشير إلى تفكير الفرد الموجه نحو الهدف، أما المكون السلوكي للأمل فهو التخطيط ثم سلك ملك الطرق لتهن التفيذ وتحقيق الأهداف التي يضعها الفرد لتحقيقها (Snyder, Irving, \& Anderson، 1991). فيروس كورونا: هي فصيلة كبيرة من الفيروسات التي قد تسبب المرض الانسان. ومن المعروف أن عددا من فيروسات كورونا تسبب لدى البشر حالات عدوى الجهاز التنفسي التي تتراوح حدتها من نزلات البرد الشائعة إلى في الى الامراض الاشد وخامة مثل متلازمة الشرق الاوسط التنفسية والمتلازمة التنفسية الحادة الوخيمة (السارس). ويسمى فيروس كورونا المكتشف مؤخرا مرض فيروس كورونا كوفيد - 19 (دليل منظمة الصحة العالمية،

- الطلاق العاطفي Emotional Divorce: يعرف كليمورEilmour (2004) الطلاق العاطفي Emotional Divorce عل أنه "عيش الزوجين في بيت واحد لكنهما منفردين ومنعزلين عن بعضهما البعض، ولم يصلا إلى مرحلة الطلاق القانوني". ويعرف إجرائيا للطلاق العاطفي بالدرجة الكلية التي يحصل عليها المتزوجين عن طريق الاستجابة على فقرات مقياس الطلاق العاطفي المطور لأغراض البحث الحالي.

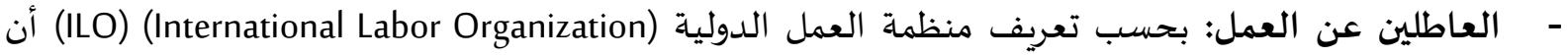
العاطل عن العمل هو الفرد البالغ من العمر (15-65) عامًا ولا يعمل رغم أنه قادرًا عليه، وراغبًا فيه، ويبحث العثاء عنه، ويقبله عند مستوى الأجر السائد، ولكن دون جدوى (Dunod، 1999). ويجب أن يتوفر عند الفرد شرطان

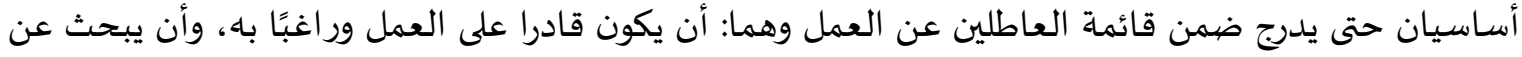
فرصة للعمل (Probest، 2005). ويعرف اجرائيا بأنه مجموعة من المتزوجين والذين ليس لديهم عمل حالي لمدة

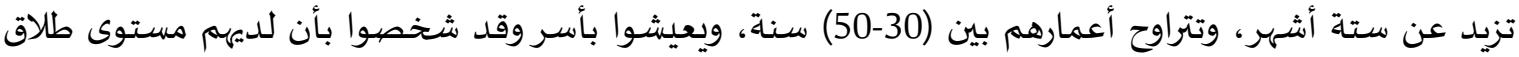
عاطفي متوسط أو مرتفع.

2- 2 - الأبحاث والدراسـات السابقة: تناولت الدراسات السابقة العديد من المتغيرات المرتبطة بالطلاق العاطفي واستخدم بعضها برامج علاجية،

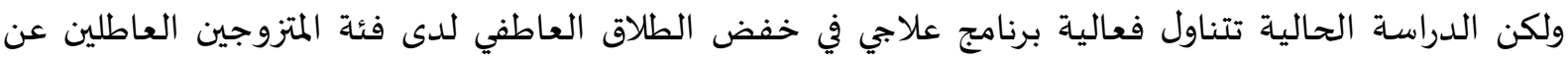

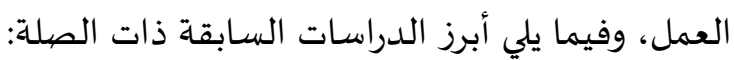
- فقد أجرى كل من كارل وتيان (1999،Karl \& Tian) دراسة هدفت إلى التنبؤ بتكرار البحث عن العمل والصحة

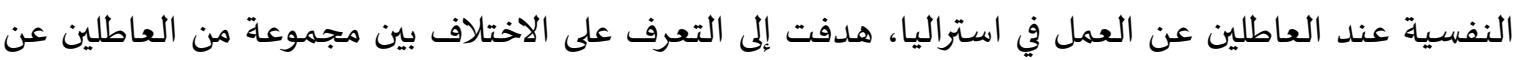

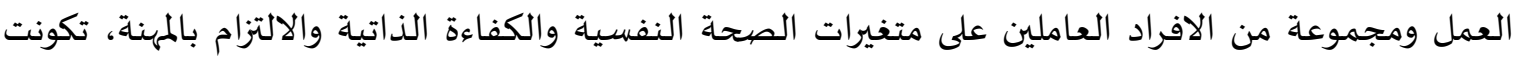

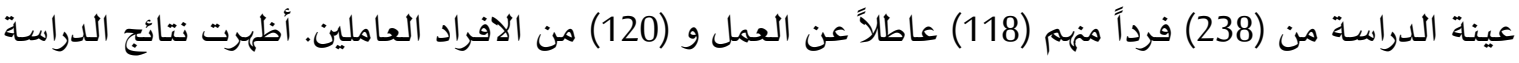

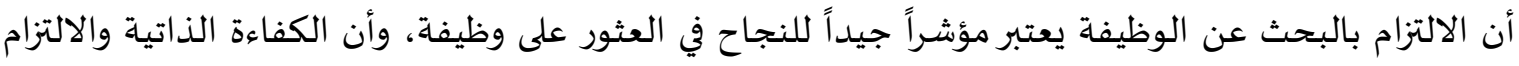
بالبحث عنها يشير إلى أن العاطلين عن العمل الذين لديهم رغبة قوية بالحصيول على الوظيفة أقل احتمالاً أن 
يعانوا من انخفاض في تقدير الذات، وان الافراد العاملين لم يكن لديهم التزام بالمهنة حيث لم يكونوا في الوظيفة التي يطمحون اليها.

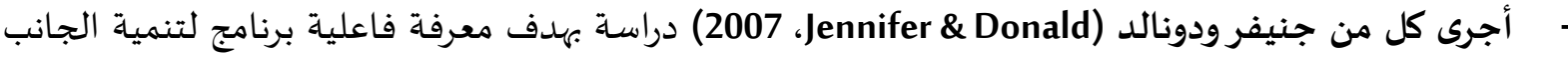
(السلوكي، المعرفي، الوجداني) لدى (25) زوجاً يعانون من اضطراب في العلاقة، وتم تطبيق البرنامج، وأظهرت

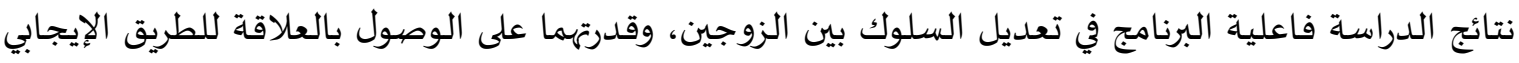

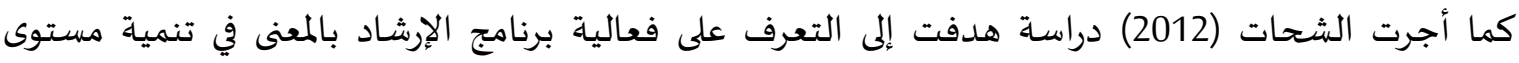

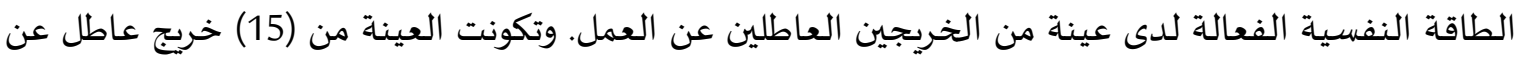

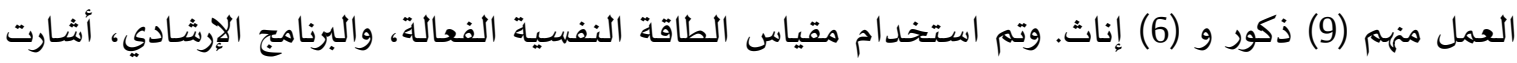

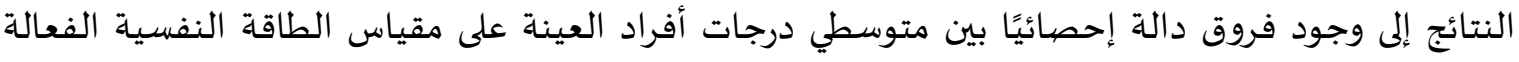

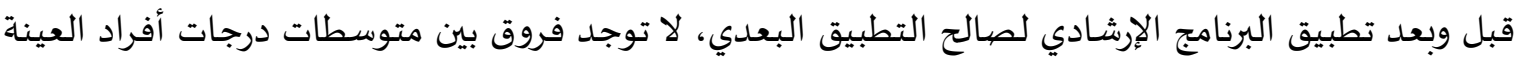
من الذكور والإناث بعد تطبيق البرنامج الإرشادي بالمعنى على مقياس الطاقة النفسية الفعالة.

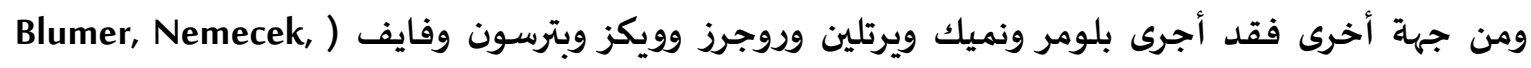
(Hertlein, Rogers, Weeks, Petrson, \& Fife

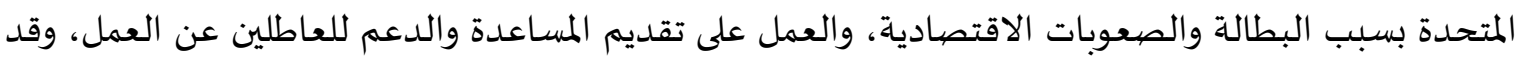

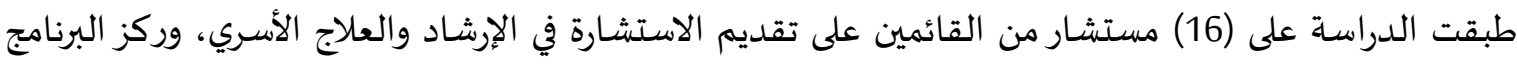

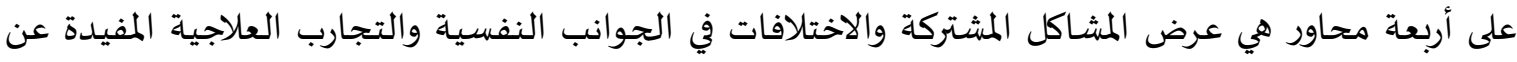

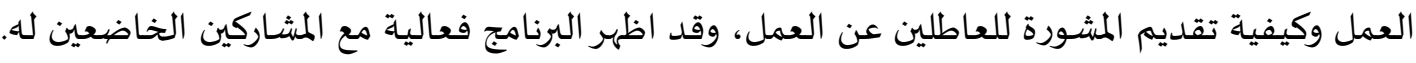
وهدفت دراسة مصطفى ومحمد وخليل (2016) للتعرف على العلاقة بين الضغوط الأسرية والطلاق العاطفي العاني

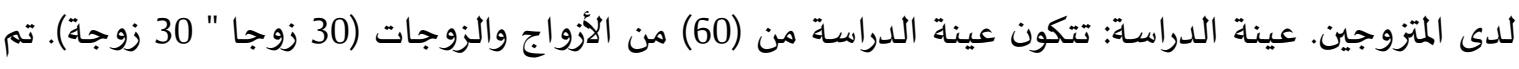

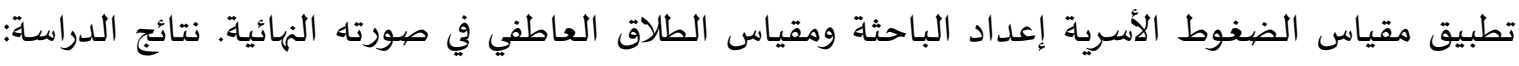
أظهرت النتائج وجود علاقة ارتباطيه موجبة بين الضغوط الأسرية والطلاق العاطفي لدى المتزوجين، أي كلما

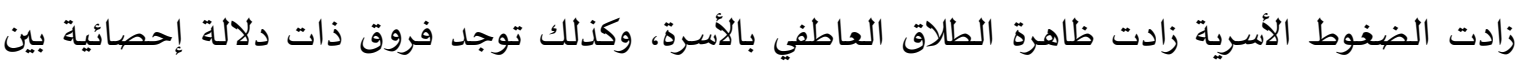

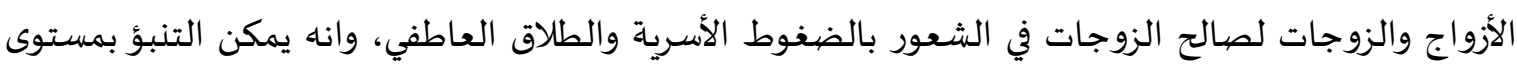

$$
\text { الطلاق العاطفي من حجم الضغوط الأسوجات الترجية }
$$

وقد تناولت دراسة الريماوي والشويكي (2017) التعرف إلى مستوى الطلاق العاطفي لدى الأزواج في محافظة

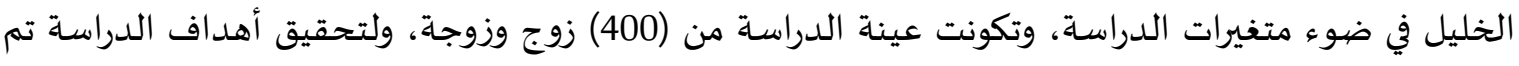
تطبيق مقياس الطلاق العاطفي من إعداد منصور، وأظهرت النتائج وجود فروق ذات ذات دلالة إحصائية فئية فل فل من: مستوى الطلاق العاطفي لدى الأزواج يعزى لمتغير الجنس وكانت الفروق لصاف لصالح الإناث، ولمتغير العمر كانت

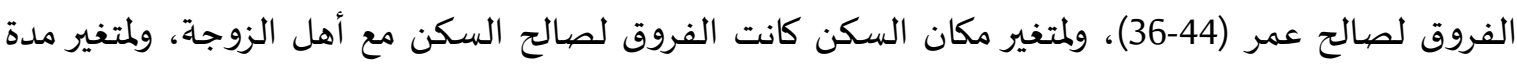

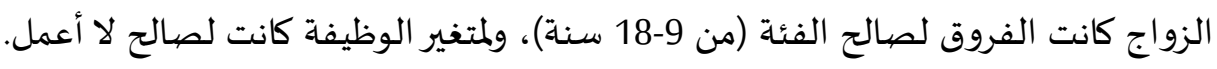
كما أجرى الجوازنة (2018) تحديد مستوى الطلاق العاطفي لدى الزوجين ومستوى التوافق النفسي للأبناء،

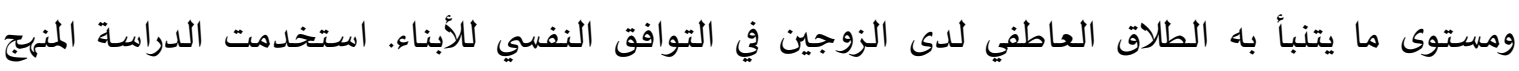

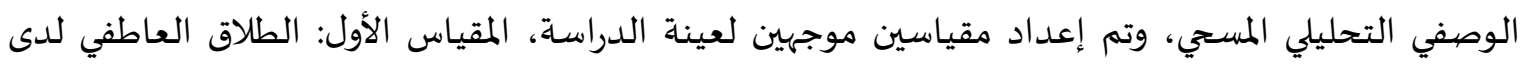

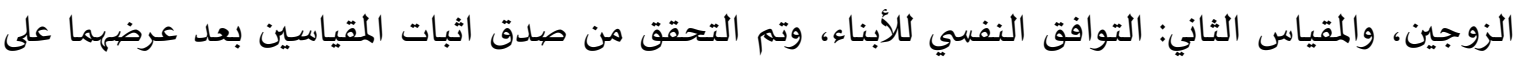

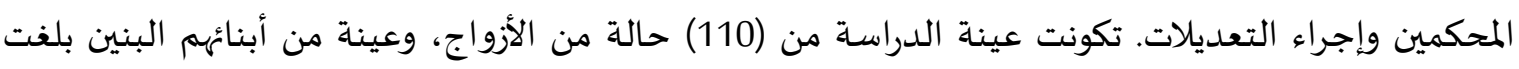


(110) طالباً. أظهرت النتائج أن المتوسطات الحسابية جاءت مرتفعة للأزواج من حيث الطلاق العاطفي،

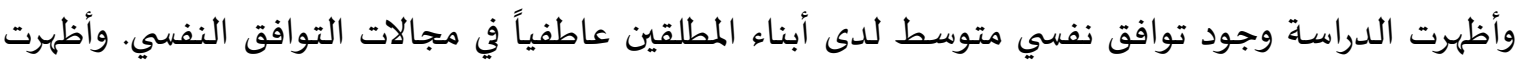

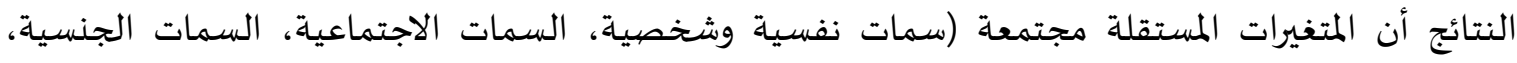

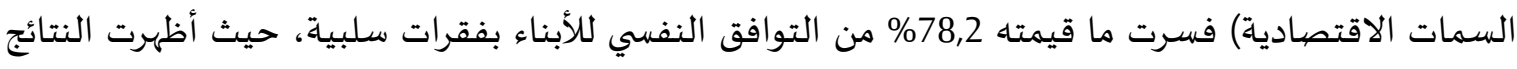

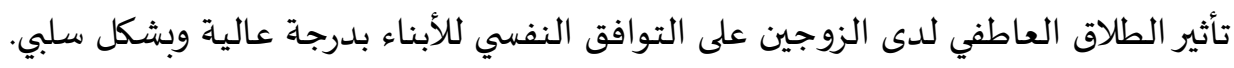

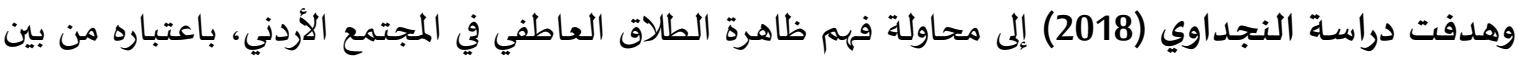

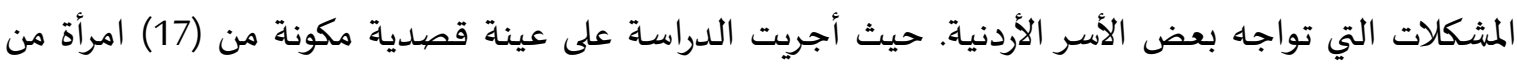

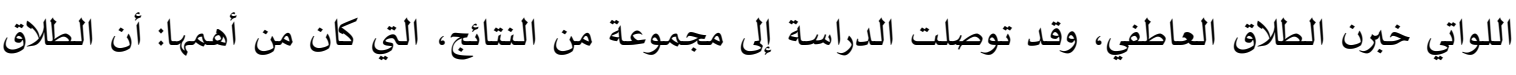

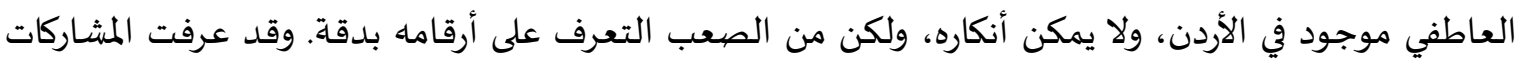

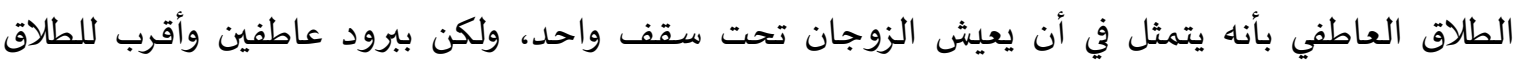

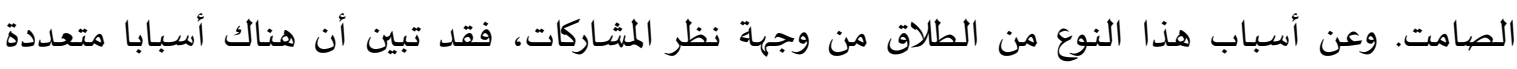
ومتداخلة، ومن الصعب حصرها لبدة اسبابة.

وهدفت دراسة الحميري (2019) الكشف عن فعالية برنامج إرشادي انتقائي تكاملي للحد من الصمت الصدا الزوجي وتحسين التوافق النفسي لدى عينة من المتزوجات حديثا. وطبّق هذا البحث على عينة مكونة من (100) طالبة إندان

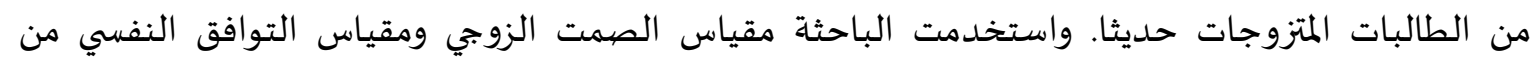
إعدادها، وكشفت نتائج الدراسة عن وجود فروق ذات دلالة إحصائية بين متوسطي درجات الطالبات المات في الميات

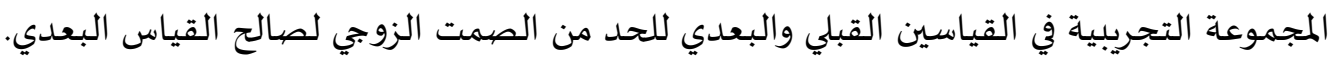

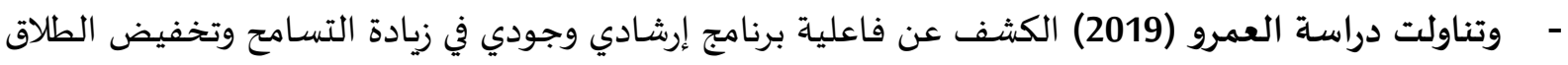

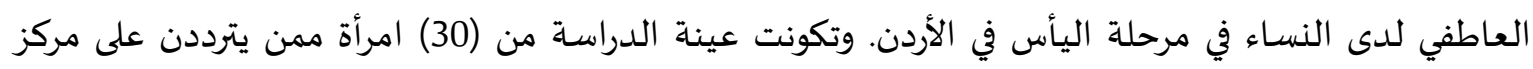

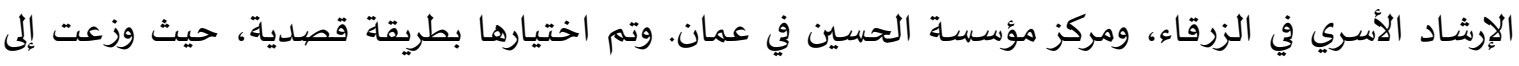

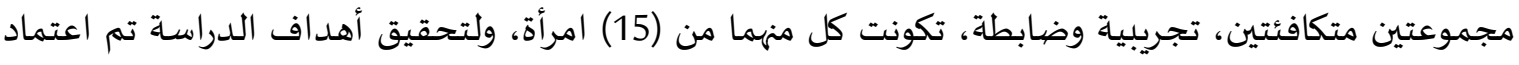

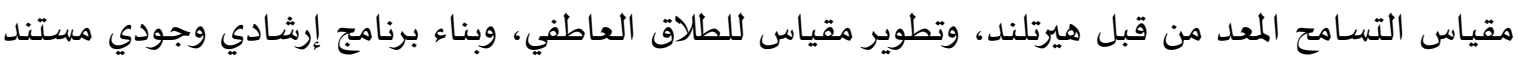

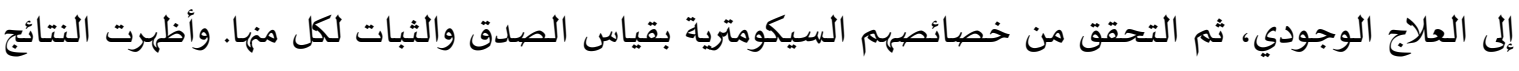

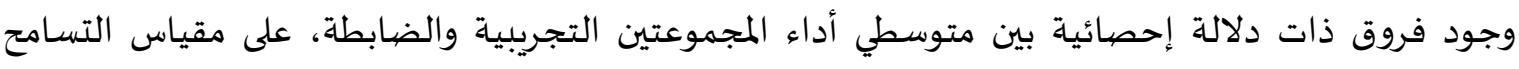

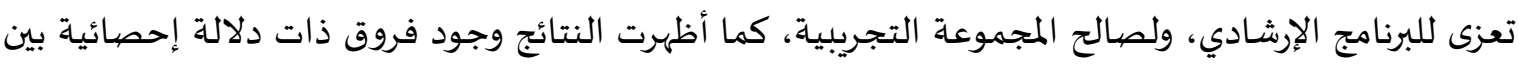

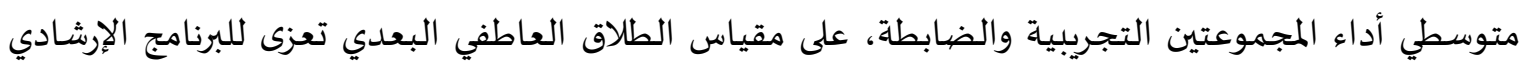
ولصالح المجموعة التجريبية بين متوسطي أداء المجموعتين. وتناولت دراسة مصطفى، وعويضة، ومحمود، وعبد الرحمن (2019) معرفة مستوي الطلاق العاطفي لدي

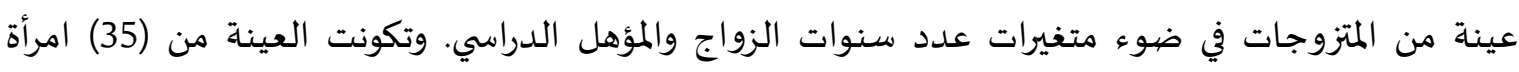
متزوجة، وتم استخدام مقياس الطلاق العاطفي إعداد الشواشرة، وعبد الرحمن (2018)، وأظهرت الثرات النتائج

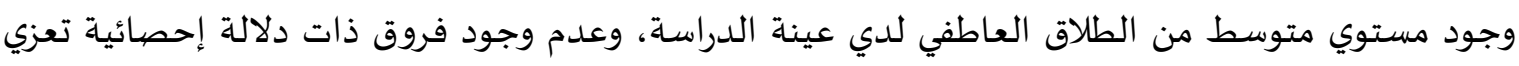

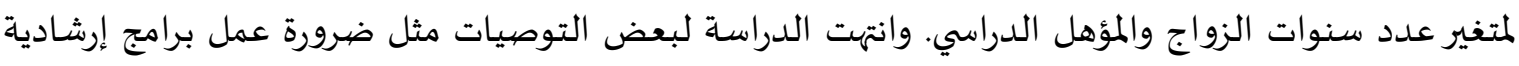

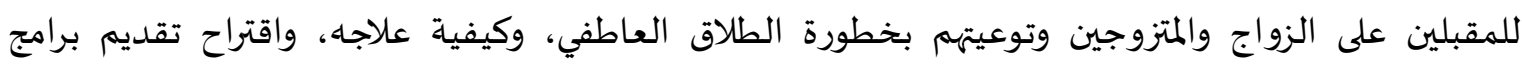

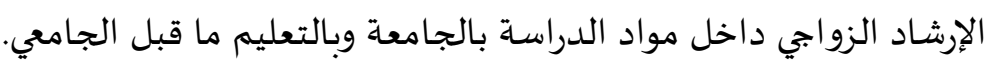


- كما تناولت دراسة شويخ (2020) ادراك جائحة كوفيد 19 كحدث صدمي وأثره في بعض الاختلالات النفسية

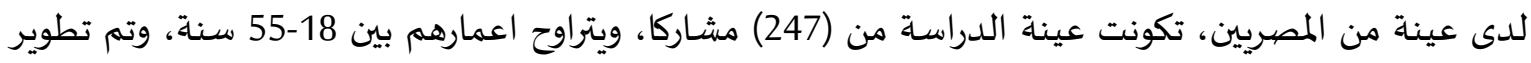

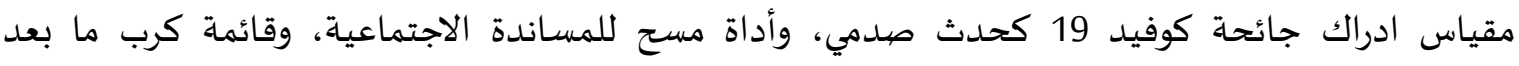

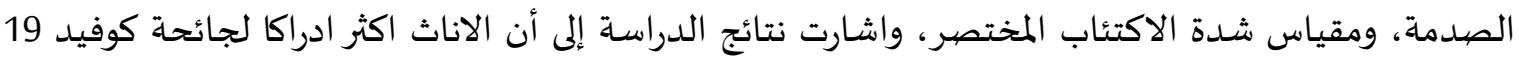

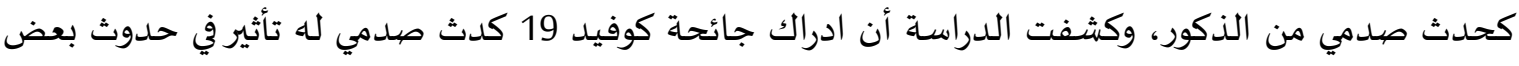

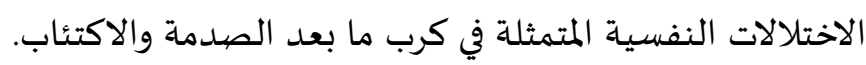

التعقيب على الأبحاث والدراسـات السابقة: يلاحظ من استعراض الدراسات والأبحاث السابقة تنوع تطرقها لمتغيرات البحث فبعضهها ركز على دراسة

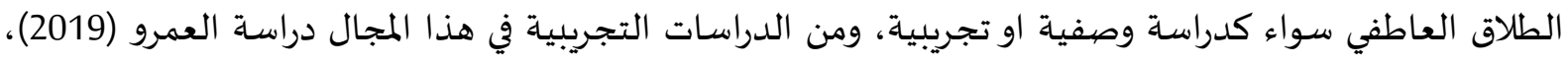

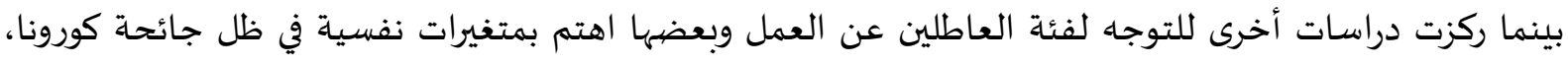

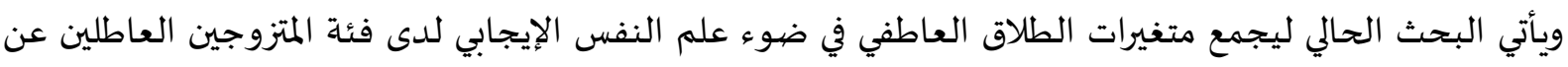

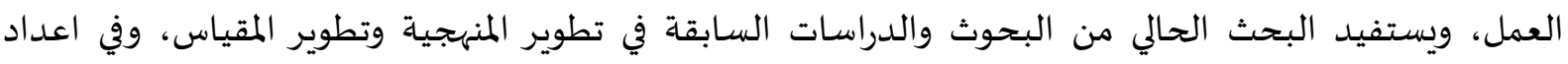
البرنامج الإرشادي، وعند مناقشة النتائج.

3- منهجية البحث وإجراءاته.

منهجية البحث:

تم استخدام المنهج شبه التجريبية لمناسبته للدراسة الحالية

مجتمع البحث:

تكون مجتمع الدراسة من جميع المتزوجين العاطلين عن العمل من المراجعين لدى المركز، حيث تصل نسبة

المتزوجين غير العاملين من المراجعين لدى المركز بين (15-20\%).

عينة البحث:

تم اختيار عينة للبحث الاستطلاعية للتأكد من مناسبة أدوات الدارسة ويبلغ عددها (30) متزوج عاطل عن

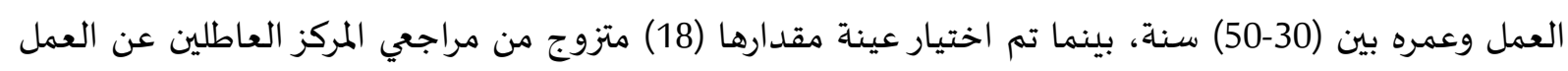

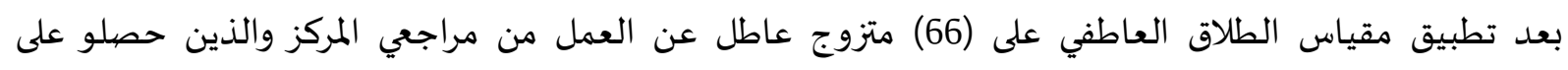

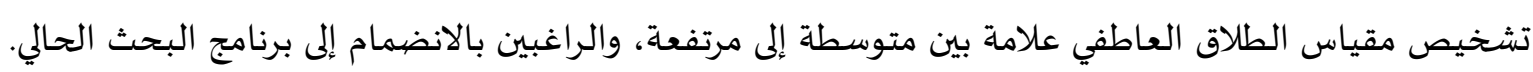

أدوات البحث:

أولا: مقياس الطلاق العاطفي اعداد الباحث تم تطوير مقياس الطلاق العاطفي، ويهتم المقياس بالتعرف على انتشار ظاهرة الطلاق العاطفي لديهم وتم اعلمادئ

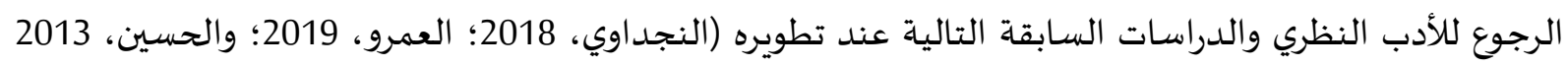
والجوازنة، 2018)، وعدد فقرات المقياس بالصيورة الأولية هو (32) فقرة وتقيس الأبعاد الأربعة التالية: 
1- الوضع الشخصي والاجتماعي داخل الحياة الأسرية: ويهتم بالصفات والسمات النفسية الانفعالية اثناء وجود

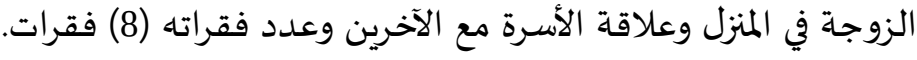

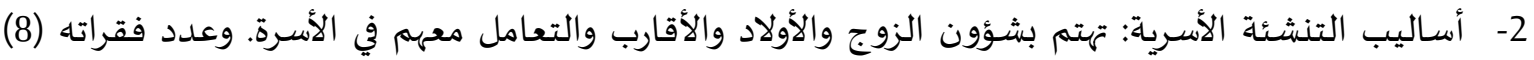
فقرات. 3- الحياة الحميمية: طبيعة الرضا عن الحياة العاطفية والرضا عنها. وعدد فقراته (8) فقرات.

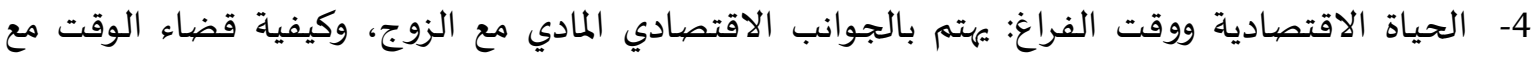

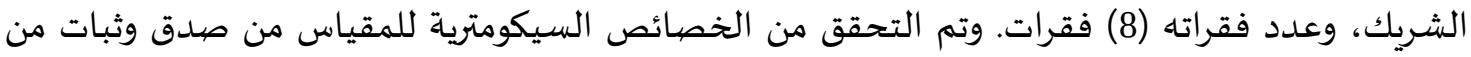

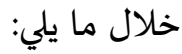
وتم التحقق من دلالات صداق بطريقتين هما:

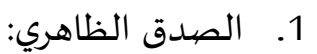

تم عرض مقياس الطلاق العاطفي بصورته الأولية على (10) محكمين من المتخصصين في الإرشاد النفسي في الجامعات الأردنية، للتعرف على آرائهم ومقترحاتهم حول ملائمة فقرات المقياس وسلامة صياغته اللغوية وقياساه

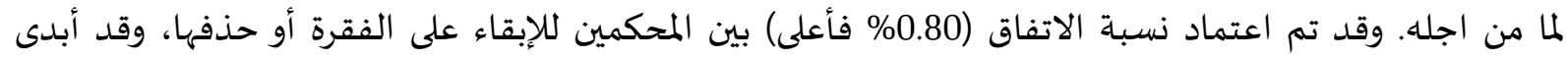
المحكمون عدداً من الملاحظات، حيث تم تعديل (3) فقرات وبقي عدد الفقرات (32) فقرة.

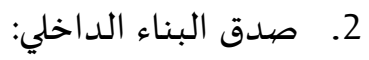

تم التحقق من صدق البناء الداخلي لمقياس الطلاق العاطفي باستخدام طريقة البناء الداخلي حيث تم

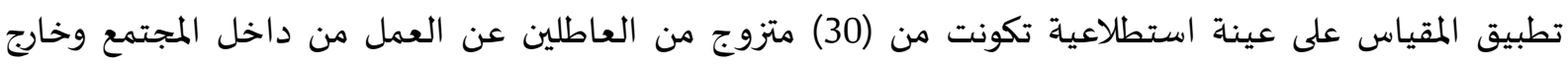

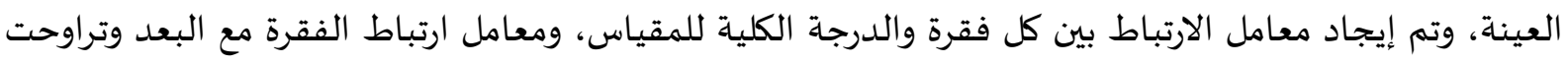
القيم بين الفقرة والدرجة الكلية للمقياس بين (0.33-0.71)، وتراوحت القيم بين الفقرات والأبعاد بين (0.30-0.62)، وهذا مؤشر على الصددق البناء الداخلي للمقياس.

\section{ثبات مقياس الطلاق العاطفي:}

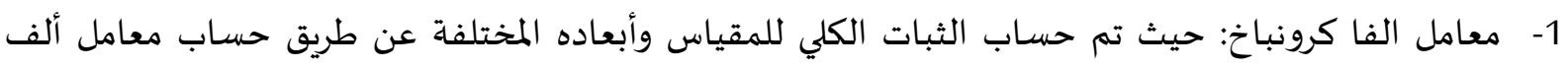
كرونباخ وبلغ للدرجة الكلية (0.89)، وللأبعاد الوضع الشخصيث الثبات الاجتماعي (0.84) وأساليب التنشئة الأسرية

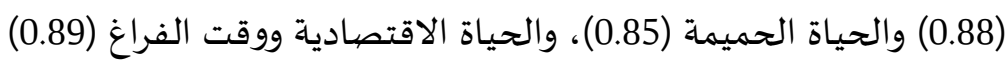

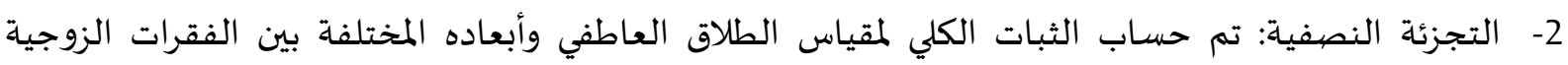

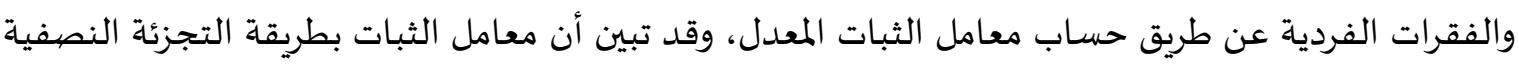

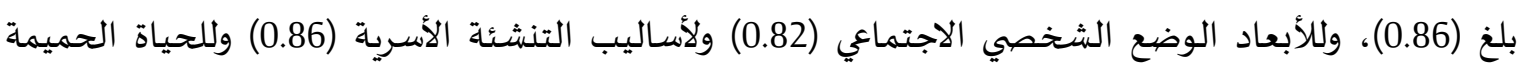

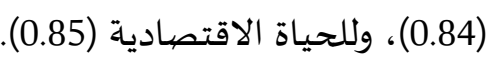
3- طريقة إعادة الاختبار: كما تم حساب الثبات بطريقة الإعادة من خلال تطبيقه على العينة الاستطلاعية

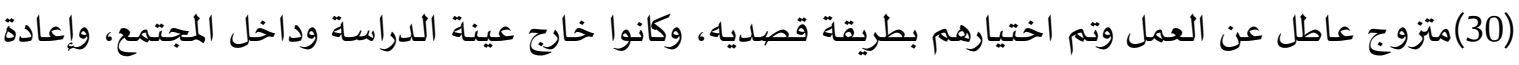

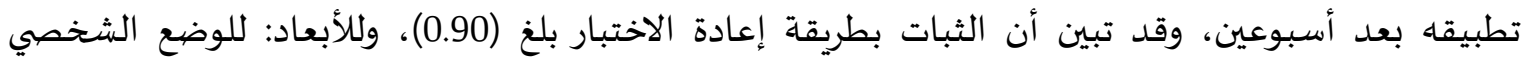

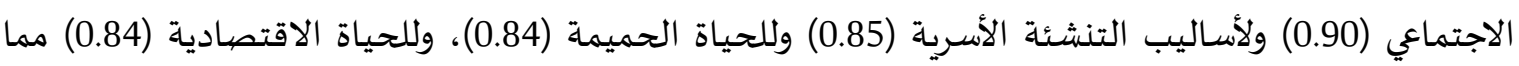
يدل على وجود درجة مناسبة من الثبات. 
يتكون المقياس من أربعة أبعاد وجميع الفقرات ذات اتجاه سلبي تدل على وجود طلاق عاطفي، ويتم الاجابة

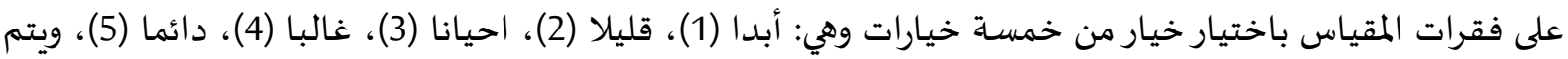
تفسير الدرجات حسب المعادلة التالية لكل بعد: المدى= أكبر قيمة - أقل قيمة /عدد الفئات، فالمدى = 4-3/1،

المدى = 1، ويمكن تفسير الدرجات التي يحصل علهها الكبير في السن على مستوى الفقرة على النحو الآتي: الدرجة (1) 2.33) مستوى منخفض من الطلاق العاطفي، و (2.34-3.66) مستوى متوسط من الطلاق العاطفي، و (3.67-5) مستوى مرتفع من الطلاق العاطفي.

ثالثا: البرنامج الإرشادي المستند إلى علم النفس الإيجابي

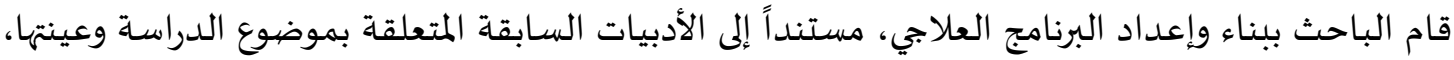
وفقاً للعلاج علم النفس الإيجابي، وتكون البرنامج العلاجي من أربعة عشر جلسـة إرشادية، مدة كل منها (60) دقيقة.

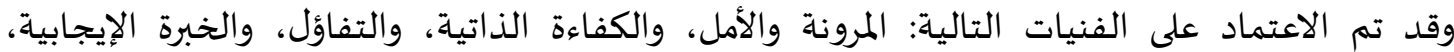

والتدفق النفسي، والصهابة النفسية.

\section{خطوات بناء البرنامج العلاجي:}

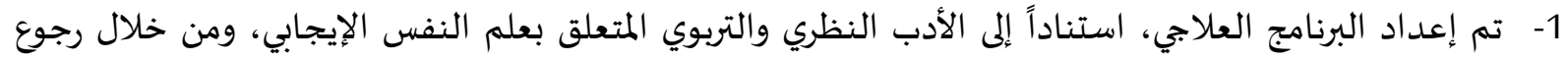

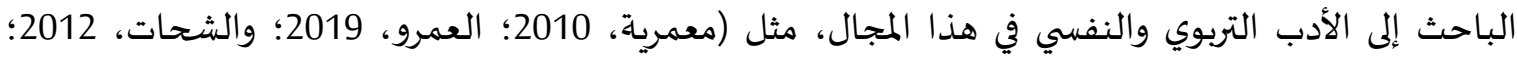

والحميري وقطحان، 2019).

2- تم تحديد الهدف العام من البرنامج، والتأكد من شمولية ودقة البرنامج الإرشادي في علم النفس الإيجابي، وذلك

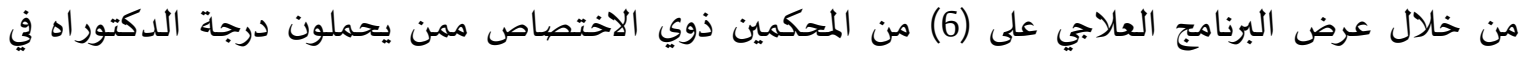

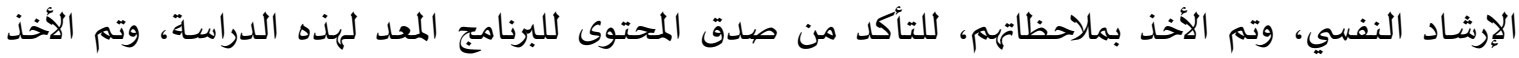
بملاحظاتهم.

تم تطبيق البرنامج العلاجي المستند إلى علم النفس الإيجابي وقد تكون البرنامج في صورته النهائية من (14) جلسة مدة كل جلسـة (45) دقيقة، وتشتمل الجلسات على مايلي.

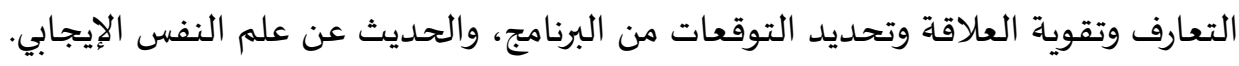

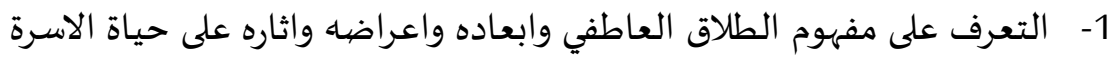
2- التعرف على أسباب الطلاق العاطفي والاستراتيجيات المناسباه لمواجهتها

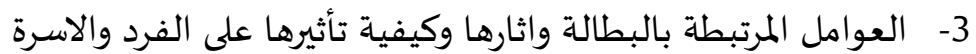

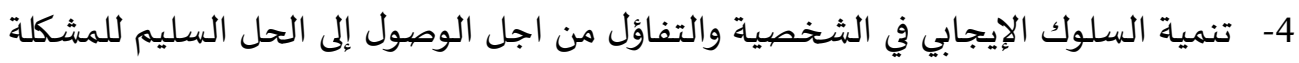
5- الاستماع للآخرين بانفتاح ومرونة

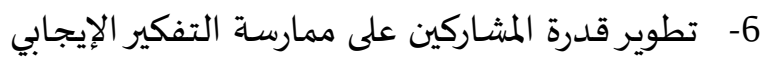

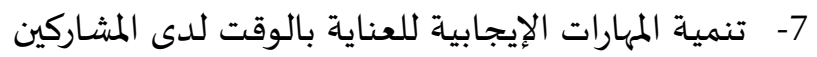
8- - غرس الأمل والخبرة الإيجابية الذاتية 9- تدريب المشاركين على الرضا عن الحياة

10- تمكين المشاركين من إيجاد طرق تساعد في الوصول الرفاهين الرفية النفسية وإلى السعادة بالحياة

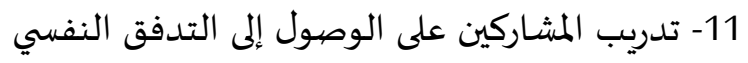


12- تدريب المشاركين على الوصول إلى المرونة النفسية التحكم والالتزام والتحدي للضغوطات

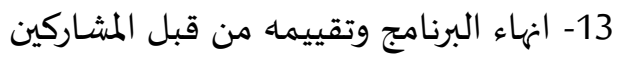

$$
\text { إجراءات البحث: }
$$

1. تم الاطلاع على الأدب النظري والدراسات السابقة حول موضوع الدراسة الحالية. 2. تم اخذ الموافقة من مدير المركز الوطني لتأهيل المجتمعي لإجراء تطبيق الماديق البرنامج.

3. تم تطوير مقياس الطلاق العاطفي بالرجوع للأدب النظري السابق.

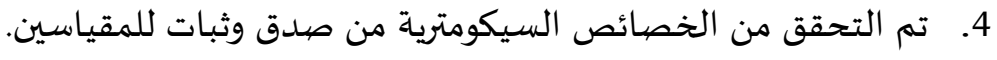

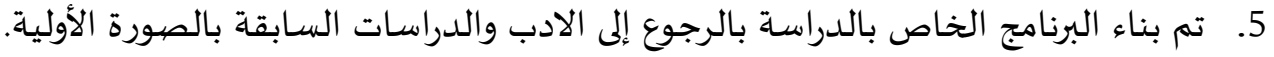

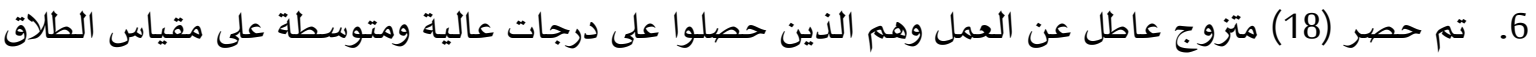
العاطفي وتم توزيعهم عشوائيا مناصفة إلى مجموعتين ضابطة وتجريبيه وتم التحقق من تكافؤ المجموعتين قبل التطبيق في القياس القبلي في المقياسين. 7. تم بناء وتحكيم البرنامج الإرشادي الذي يتكون من (14) جلسة إرشاديه بصورته النهائية بواقع (45) دقيقه

$$
\text { لكل جلسـة إرشادياه. }
$$

8.

9. كما تم اجراء القياس البعدي على افراد المجموعتين التجريبية والضابطة.

10. تم اجراء القياس التتبعي بعد مرورشهرمن تطبيق البرنامج على المجموعة التجريبية.

11. تم تحليل البيانات المتجمعة وتفسيرها ومناقشتها والوصهول إلى التوصيات المناسبة.

\section{4- - نتائج البحث ومناقشتها: فيما يلي استعراضا لنتائج الدراسـة ومناقشتها:}

قبل البدء بتنفيذ تطبيق البرنامج العلاجي المستند إلى علم النفس الإيجابي تم التحقق من تكافؤ توزيع أفراد عينة الدراسة على المجموعتين (التجريبية، الضابطة) لمستوى الطلاق العاطفي، وفحص الفروق بينهما باستخدام

\begin{tabular}{|c|c|c|c|c|c|c|c|}
\hline مستوى & Z & مان وتني U & الرتب مجموع & متوسط الرتب & العدد & المجموعة & المجال \\
\hline \multirow{2}{*}{0.16} & \multirow{2}{*}{$1.47-$} & \multirow{2}{*}{24.00} & 102.00 & 11.33 & 9 & التجربيية & \multirow{2}{*}{ الوضيع النفسي } \\
\hline & & & 89.00 & 7.67 & 9 & الضيابطة & \\
\hline \multirow{2}{*}{0.09} & \multirow{2}{*}{$1.78-$} & \multirow{2}{*}{21.00} & 105.00 & 11.67 & 9 & التجريبية & \multirow{2}{*}{ أساليب التنشئة } \\
\hline & & & 66.00 & 7.33 & 9 & الضيابطة & \\
\hline \multirow{2}{*}{0.55} & \multirow{2}{*}{$0.68-$} & \multirow{2}{*}{33.00} & 78.00 & 8.67 & 9 & التجريبية & \multirow{2}{*}{ الحياة الحميمية } \\
\hline & & & 93.00 & 10.33 & 9 & الضابطة & \\
\hline
\end{tabular}
اختبار (Mann-Whitney) اللامعلمي والجدول (1) يوضين (1) التجرئه نتائج ذلك. جدول (1): نتائج اختبار (Mann-Whitney) للتعرف على دلالة الفروق بين المجموعتين التجريبية والضيطابطة على مقياسي الطلاق العاطفي في القياس القبلي 
المجلة العربية للعلوم ونثر الأبحاث ـ مجلة العلوم التربوية والنفسية ـ المجلد الخامس ـ العدد السادس و الثلاثون ـ سبتمبر 2021م

\begin{tabular}{|c|c|c|c|c|c|c|c|}
\hline مستوى الدلالة & $\mathbf{Z}$ & مان وتني U & الرتب & متوسط الرتب & العدد & المجموعة & المجال \\
\hline \multirow{2}{*}{0.39} & \multirow{2}{*}{$0.94-$} & \multirow{2}{*}{30.00} & 96.00 & 10.67 & 9 & التجريبية & \multirow{2}{*}{ الاقتصادية الحياة } \\
\hline & & & 75.00 & 8.33 & 9 & الضابطة & \\
\hline \multirow{2}{*}{0.07} & \multirow{2}{*}{$1.89-$} & \multirow{2}{*}{19.00} & 107.00 & 11.89 & 9 & التجريبية & \multirow{2}{*}{ الطلاق العاطفي } \\
\hline & & & 64.00 & 7.11 & 9 & الضابطة & \\
\hline
\end{tabular}

يلاحظ من خلال الجدول (1) عدم وجود فروق بين المجموعتين التجريبية والضابطة في مستوى الطلاق العاطفي على الاختبار القبلي، ويتبين من ملاحظة قيمة Z للطلاق العاطفي أهها كانت غير دالة إحصائيا وبلغت (1) (0.07)

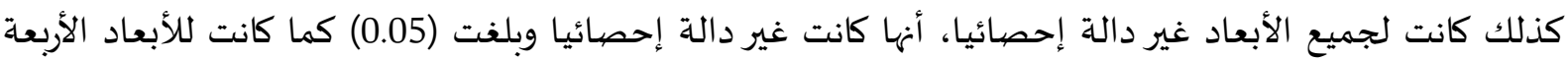

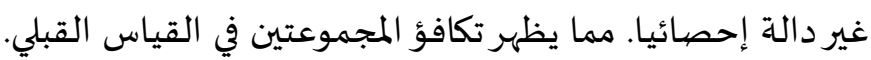
نتيجة السؤال الأول: هل هناك فروق ذات دلالة إحصائية عند مستوى (0.05) بين رتب متوسطات

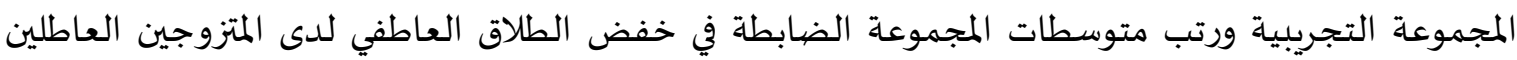

$$
\text { عن العمل في فترة انتشار فيروس كورونا؟ }
$$

ولإجابة عن السؤال الحالي تم فحص الفروق بينهما باستخدام اختبار (Mann-Whitney) اللامعلمي للتأكد

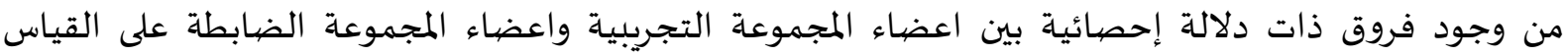
البعدي في تحسن الطلاق العاطفي، والجدول (2) يوضح دون نتائج ذلك. جدول (6): نتائج اختبار (Mann-Whitney) للتعرف على دلالة الفروق بين المجموعتين التجريبية والضيابطة على مقياس الطلاق العاطفي في القياس البعدي

\begin{tabular}{|c|c|c|c|c|c|c|c|c|}
\hline مربع حجم الأثر & مستوى الدلالة & Z & مان وتني & الرتب & متوسط & 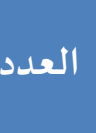 & المجموعة & المجال \\
\hline \multirow{2}{*}{0.35} & \multirow{2}{*}{0.02} & \multirow{2}{*}{$2.29 *$} & \multirow{2}{*}{14.50} & 59.50 & 6.61 & 9 & التجريبية & \multirow{2}{*}{ الوضع النفسي } \\
\hline & & & & 111.50 & 12.39 & 9 & الضابطة & \\
\hline \multirow{2}{*}{0.46} & \multirow{2}{*}{0.00} & \multirow{2}{*}{$3.10^{* *}$} & \multirow{2}{*}{5.50} & 50.50 & 5.61 & 9 & التجريبية & \multirow{2}{*}{ أساليب التنشئة } \\
\hline & & & & 120.50 & 13.39 & 9 & الضابطة & \\
\hline \multirow{2}{*}{0.55} & \multirow{2}{*}{0.00} & \multirow{2}{*}{$3.32^{* *_{-}}$} & \multirow{2}{*}{3.00} & 48.00 & 5.33 & 9 & التجريبية & \multirow{2}{*}{ الحياة الحميمية } \\
\hline & & & & 123.00 & 13.67 & 9 & الضابطة & \\
\hline \multirow{2}{*}{0.83} & \multirow{2}{*}{0.00} & \multirow{2}{*}{$3.58^{* *}$} & \multirow{2}{*}{0.00} & 45.00 & 5.00 & 9 & التجريبية & \multirow{2}{*}{ الاقتصادية الحياة } \\
\hline & & & & 126.00 & 14.00 & 9 & الضابطة & \\
\hline \multirow{2}{*}{0.59} & \multirow{2}{*}{0.00} & \multirow{2}{*}{$3.49 * *_{-}$} & \multirow{2}{*}{1.00} & 46.00 & 5.11 & 9 & التجريبية & \multirow{2}{*}{ الطلاق العاطفي } \\
\hline & & & & 125.00 & 13.89 & 9 & الضيابطة & \\
\hline
\end{tabular}

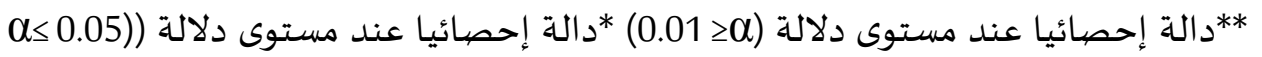
يلاحظ من خلال الجدول (2) وجود فروق بين المجموعتين التجريبية والضابطة في مستوى الطلاق العاطفي

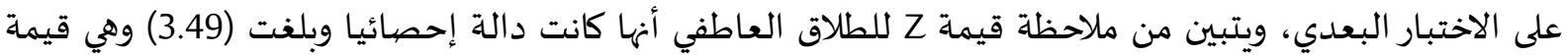


دالة إحصائيا، كذلك كانت لجميع الأبعاد ذات دلالة إحصائيا، مما يظهر فعالية البرنامج الإرشادي المستند إلى علم النفس الإيجابي في خفض الطلاق العاطفي لدى المتزوجين العاطلين عن العمل. وتتفق نتيجة الدراسة الحالية مع ما أشارت له نظرية اريكسون في النمو النفسي الاجتماعي ونظرية الذات النات

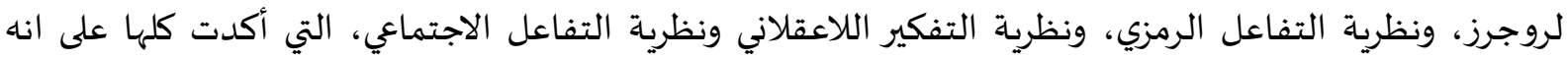
يمكن أن تتغير الجانب السلبي في الطلاق العاطفي ويمكن أن يتحسن ويتغير، وهذا ما تم خلال البرنامج الإرشادي الحالي المستند إلى علم النفس الإيجابي. ويتفق كذلك مع نتيجة دراسة جنيفر ودونالد (Jennifer \& Donald، 2007)، ودراسة النجداوي (2018) ودراسة الحميري (2019)، ودراسة العمرو (2019)، ودراسة بلومر ونميك ويرتلين وروجرز وويكز وبترسون وفايف (2014، Blumer, Nemecek, Hertlein, Rogers, Weeks, Petrson, \& Fife) العاطفي من خلال البرامج الإرشادية.

ويعزى تحسن أعضاء المجموعة التجريبية مقارنة مع المجموعة الضابطة نظرا لطبيعة البرنامج الإرشادي المستند إلى علم النفس الإيجابي والذي تضمن التركيز على الجانب الإيجابي بعيدا عن الجوانب السلبية لدى المشاركين، مما ساعد في تحسين وتنمية الحياة الأسرية لدى المشاركين، وربما انعكس ذلك على حسن إدارئ إدارة

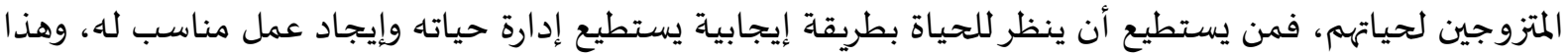
ما تم في الدراسة الحالية.

ويعزو الباحث النتيجة الحالية نظرا لطبيعة التفاعل بين المشاركين، وطبيعة الواجبات المقدمة، وطبيعة

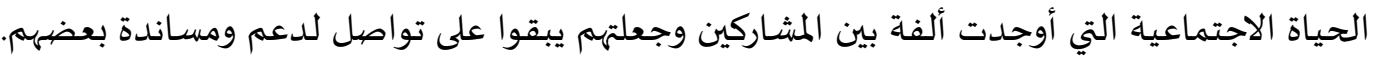
نتيجة السؤال الثاني: هل هناك فروق ذات دلالة إحصائية عند مستوى (م=0.05) بين رتب متوسطات المجموعة التجريبية في الاحتفاظ بمستوى الانخفاض في الطلاق العاطفي لدى المتزوجين العاطلين عن العمل في

فترة انتشار فيروس كورونا؟

ولإجابة على السؤال؛ تم تطبيق مقياسي الدراسة الطلاق العاطفي على أعضاء المجموعة التجريبية بعد

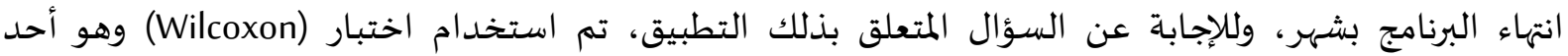
الاختبارات اللامعلمية الملائمة للكشف عن الفروق بين التطبيقين البعدي والتتبعي في حالة العينات الصغيرة الحجم الصماء

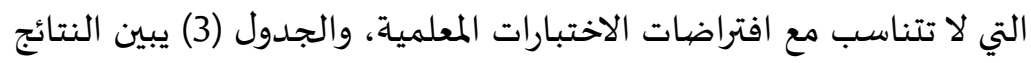

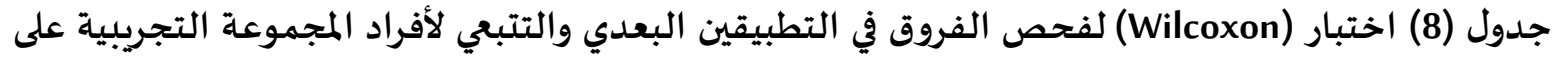
مقياس الطلاق العاطفي

\begin{tabular}{|c|c|c|c|c|c|c|}
\hline مستوى الدلالة & قيمة (Z) & مجمتوع & متوسط الرتب & عدد الرتب & توزيع الرتب & 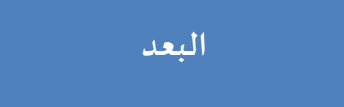 \\
\hline \multirow{3}{*}{0.51} & \multirow{3}{*}{$0.66-$} & 17.00 & 8.50 & 2 & سالبة & \multirow{3}{*}{ الوضع النفسي الاقتصيادي } \\
\hline & & 28.00 & 4.00 & 7 & 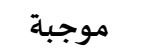 & \\
\hline & & & & $\mathbf{0}$ & 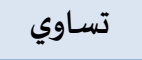 & \\
\hline \multirow{3}{*}{0.07} & \multirow{3}{*}{$1.84-$} & 7.00 & 7.00 & 1 & سـالبة & \multirow{3}{*}{ أسـاليب التنشئة الأسرية } \\
\hline & & 38.00 & 4.75 & 8 & موجبة & \\
\hline & & & & $\mathbf{0}$ & تسـاوي & \\
\hline 0.08 & $1.77-$ & 5.50 & 5.50 & 1 & سالبة & الحياة الحميمة \\
\hline
\end{tabular}


المجلة العربية للعطوم ونشر الأبحاث ـ مجلة العلوم التربوية والنفسية ـ المجلد الخامس ـ العدد السادس و الثلاثون ـ سبتمبر 2021م

\begin{tabular}{|c|c|c|c|c|c|c|}
\hline مستوى الدلالة & قيمة (Z) & مجموع الرتب & متوسط الرتب & عدد الرتب & توزيع الرتب & البعد \\
\hline & & 30.50 & 4.36 & 7 & موجبة & \\
\hline & & & & 1 & تساوي & \\
\hline \multirow{3}{*}{0.37} & \multirow{3}{*}{$0.89-$} & 15.00 & 5.00 & 3 & سالبة & \multirow{3}{*}{ الحياة الاقتصيادية } \\
\hline & & 3.00 & 5.00 & 6 & موجبة & \\
\hline & & & & $\mathbf{0}$ & تسـاوي & \\
\hline \multirow{3}{*}{0.29} & \multirow{3}{*}{$1.07-$} & 31.50 & 6.30 & 5 & سالبة & \multirow{3}{*}{ الطلاق العاطفي } \\
\hline & & 13.50 & 3.38 & 4 & موجبة & \\
\hline & & & & $\mathbf{0}$ & تسـاوي & \\
\hline
\end{tabular}

تظهر النتائج الواردة في الجدول (3) عدم وجود فروق دالة إحصائيا عند مستوى دلالة (م= 0.05) بين

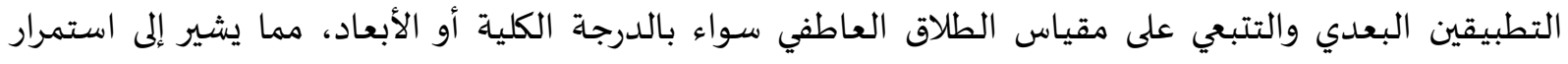

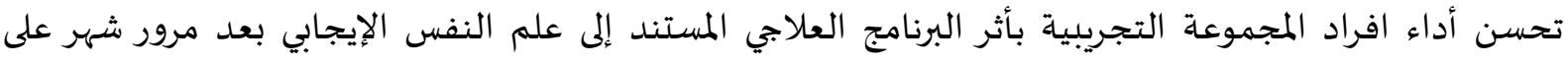
تنفيذه.

وتظهر نتيجة السؤال الحالي الاستمرار بالتحسن لدى أفراد المجموعة التجريبية رغم انتهاء البرنامج العلاجي، مما يظهر أن البرنامج الحالي قد استخدم مهارات طويلة المدى ولم يكن مجرد معلومات سرعان ما تم نسيانها،

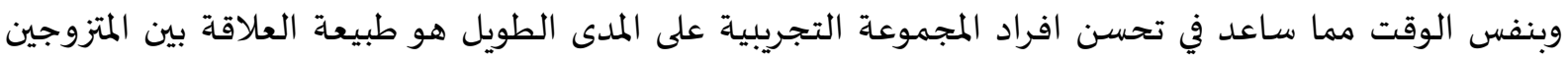
انفسهم والتواصل القائم بينهن كأفراد مجموعة تجريبية من خلال مواقع التواصل الاجتماعي، حيث أنهم شكلوا مجموعة الكترونية معا بسبب الحظروتواصلوا معا ويحثوا بعضهم على الاستفادة من المهارات التي تم التدريب عليها.

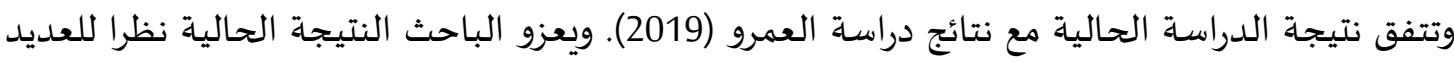

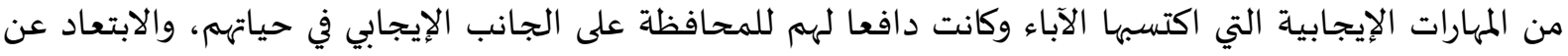

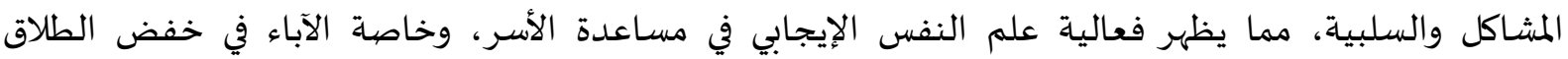
العاطفي.

\section{التوصيات والمقترحات.}

بناء على نتائج الدراسة يوصي الباحث ويقترح بما يلي:

1. الاهتمام بظاهرة الطلاق العاطفي لدى المتزوجين العاطلين عن العمل عموما لما لها من أهمية في حياتهم.

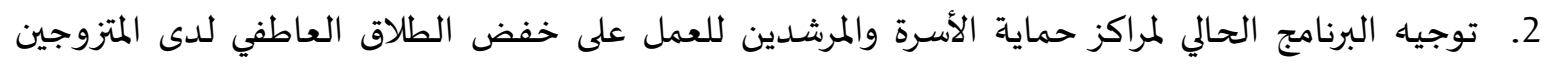

$$
\text { العاطلين عن العمل. توجله العبان. }
$$

3. العمل على مساعدة المتزوجين في تجديد الانفعالات بحياتهم لكي يصبحوا أكثر تكيفا مع التغيرات التي ترافق

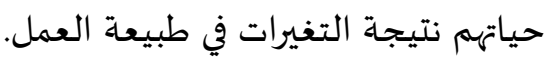

4. مراعاة فئة المتزوجين العاطلين عن العمل عموما وخاصة في الجوانب النفسية كالطلاق العاطفي.

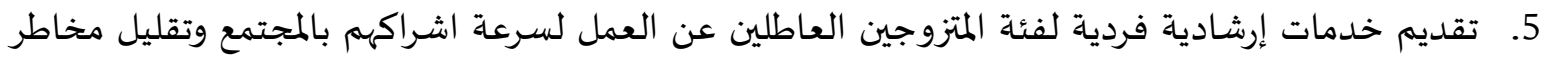
الاصيابة عليهم من الناحية النفسية وخاصة فيما يتعلق بالطلاق العاطفي. 
6. إطلاق مشروعات مجتمعية توفر الخدمات الاجتماعية والمادية والمعنوية لفئة المتزوجين العاطلين عن العمل في ظل انتشار فيروس كورونا.

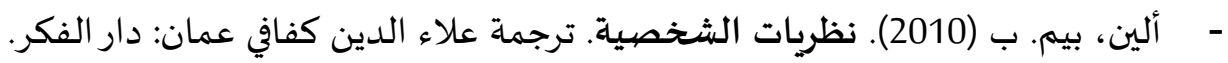

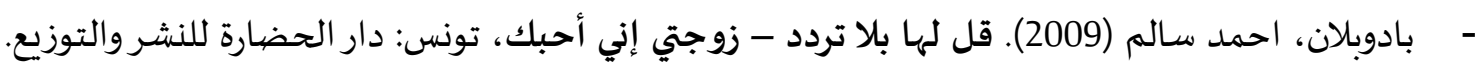

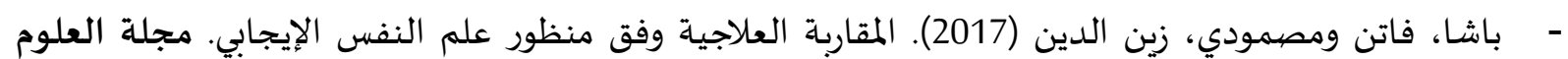

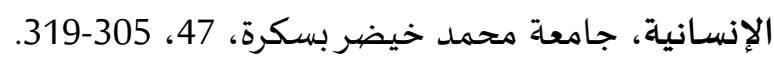

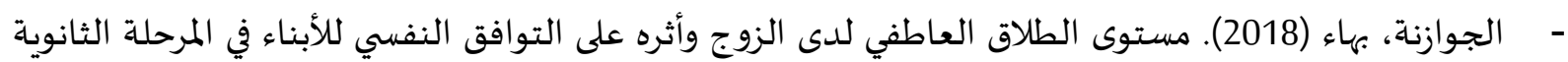

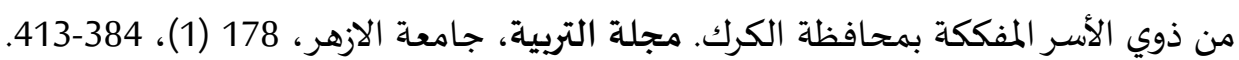

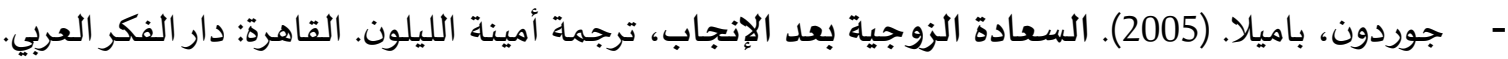

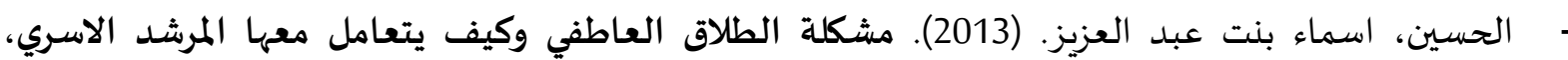
مكتبة الملك فهد الوطنية، 33-34.

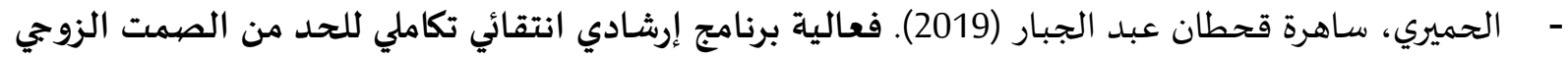

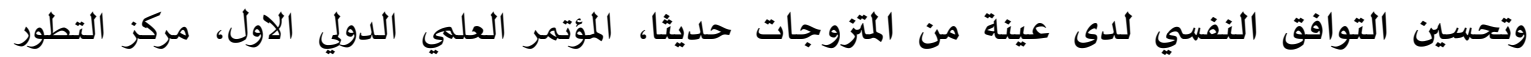

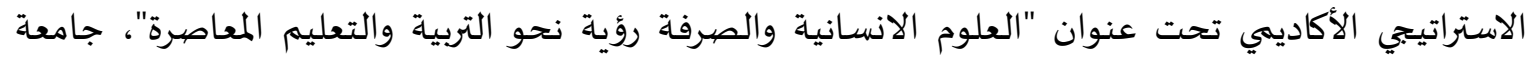

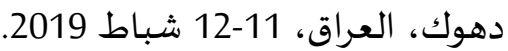

- د دائرة الإحصاءات العامة (2014). واقع البطالة في الأردن، المملكة الأردنية الهاشمية. http://dosweb.dos.gov.jo/ar - مائرة الإحصاءات العامة (2020). واقع البطالة في الأردن، المملكة الأردنية الهاشمية، http://dosweb.dos.gov.jo/ar/category رفاعي، عادل (2013). مشكلة البطالة لدى خريجي الخدمة الاجتماعية في مصر، رؤية نقاتئة نقدية، دراسة ميدانية

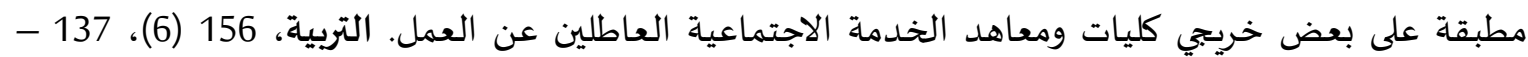

- الريماوي، عمر والشوبكي، هناء (2017). الطلاق العاطفي لدى الازواج في محافظة الخليل في ضوء متغيرات

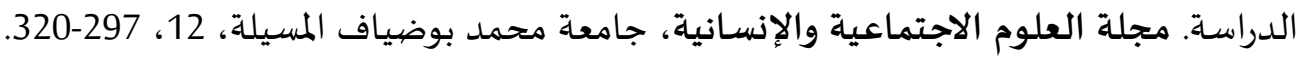

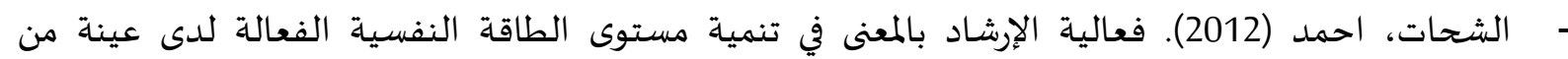
الخربجين العاطلين دارسة سيكومترية إكلينيكية، مجلة القراءة والمعرفة، الجمعية المصرية للقراءة والمعرفة، 189-1، 127 - شريفي، هناء (2016). الصحة النفسية من منظور علم النفس الإيجابي. دراسات نفسية، مركز البصيرة للبحوث والاستشارات والخدمات التعلمية، 13، 109-101-117. - شكري، علياء (2009). علم الاجتماع العائلي. عمان: دار المسيرة. 
شويخ، هناء (2020) إدراك جائحة كوفيد 19 كحدث صدمي وأثره في بعض الاختلالات النفسية لدى عينة من

المصريين، المجلة المصرية للدراسات النفسية، الجمعية المصرية للدراسات النفسية، 109 (30)، 41-78.

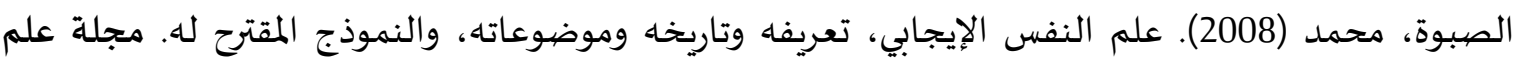
النفس، (76-79) أكتوبر 2007-أكتوبر 2008. القاهرة، الهيئة المصرية العامة للكتاب.

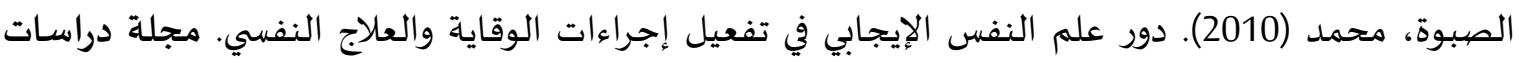

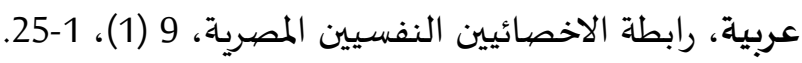
العبيدي، عفراء ابراهيم خليل. (2015). الطلاق العاطفي في ضوء بعض راهيه المتغيرات لدى الطلبة المتزوجين في

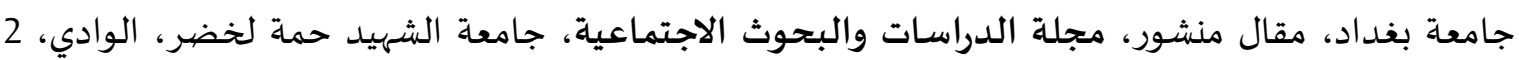
.23 ، (14)

العمرو، ناديا (2019). فاعلية برنامج إرشادي وجودي في زيادة التسامح وتخفيض الطلاق العاطفي لدى

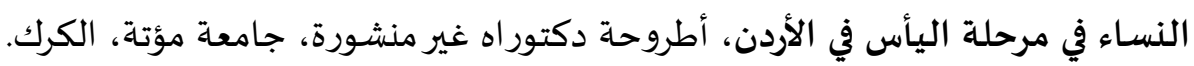

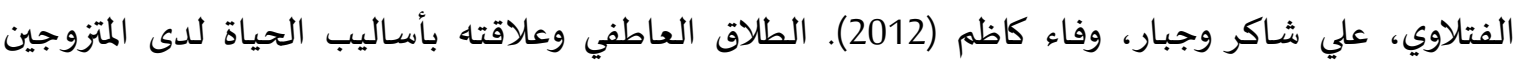
الموظفين في دوائلر الدولة، مجلة القادسية للعلوم الانسانية، جامعاة القادسية، العراق، 1 (1)، 65.

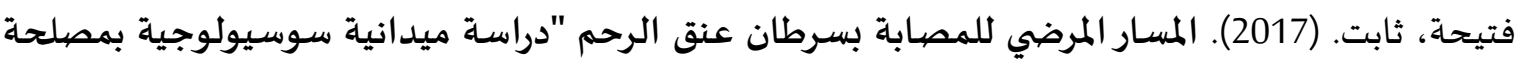
الاورام السرطانية بمستشفى يوجي بمزعزان-مستغانم. رسالة ماجستير غير منشورة. الجزائر.

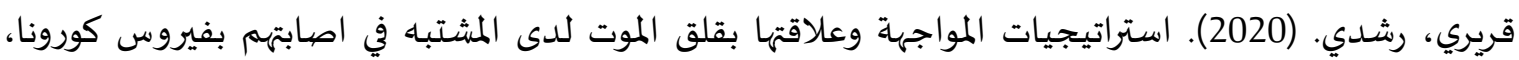

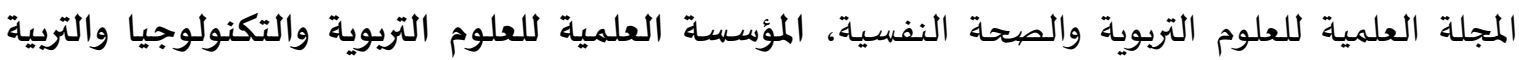
الخاصة، 2 (1)، 69-45. - كوفالوف، سيرغي (2005) سيكولوجية الحب والعلاقات الأسرية. ترجمة نزارعيون السود. دمشق: دار كنعان

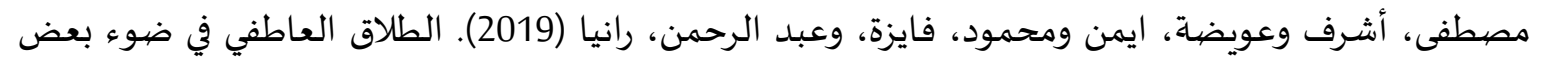

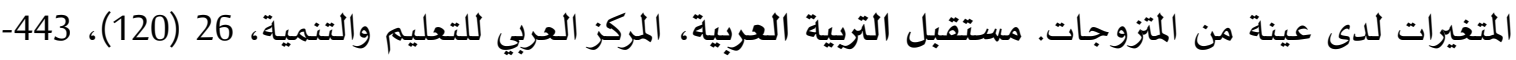
.464 مصطفى، امنية وخليل، محمد ومحمد،، عادل (2016). الضغوط الأسرية وعلاقتها بالطلاق العاطفي لدى المتزوجين. مجلة كلية التربية، جامعة بورسعيد، 20، 472-491. مصيمودي، زين الدين وباشا، فاتن (2016). علم النفس الإيجابي: تناول مفاهيمي. مجلة علمهيه علوم الانسان

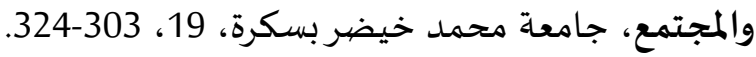
معمرياة، بشير (2010). علم النفس الإيجابي اتجاه جديد لدراسة القوى والفضائل الإنسانية. دراسات نفسية، 97-158. ، 2

منظمة الصحة العالمية، (2020)، دليل توعوي صدي شامل، الاونروا، النسخة الأولى النجداوي، أن موسى (2018). الطلاق العاطفي في المجتمع الأردني: دراسة نوعية. دراسات، العلوم الإنسانية

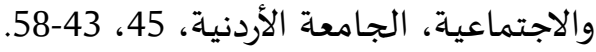

ثانيا- المراجع بالإنجليزية:

- Amiri, S.; Hekmatpour, M. \& Fadaei, M. (2015). Investigating emotional divorce on family performance. Journal of Applied Environmental and Biological Sciences, 5 (11), 782-786. 
- Blumer, M., Nemecek, R., Hertlein, K., Rogers, K., Weeks, G., Petrson, C., \& Fife, S (2014). Counseling the Unemployed: Exploring MFT Trainees' Perceptions of a Pilot Clinical Program, the American Journal of Family Therapy, 42, 205-216.

- Boman, P., Furlong, M. J., Shochet, I., Lilies, E., \& Jones, C. (2009). Optimism in the school context. In R. Gilman, E. S. Huebner, \& M.J. Furlong (Eds.), Handbook of positive psychology in schools (pp. 51-64). New York, NY: Routledge.

- Corey, G. (2013). Theory and practice of counseling and psychotherapy. Australia; Belmont, CA: Brooks.

- Dunod, D. (1999). Edition beg ET autres, macroeconomic, Paris,

- Gilmour, Glenn A. (2004). High-conflict separation and Divorce: option for consideration.Department of Justice Canada. Aussidisponible en Francis.

- Hijazi, Mustafa (2000). Mental Health, Arab Cultural Center: Morocco

- Jennifer, S. K., \& Donald, H. B. (2007). Integrating dialectical behavior therapy and cognitivebehavioral couple therapy: A couples skills group for emotion dysregulation. Cognitive and Behavioral Practice, 14 (4), 394-405. Retrieved from http://www.sciencedirect.com/science, visited in: $18 / 7 / 2019$

- Karl, W. \& Tain. O. (1999). Predicting job seeking frequency and psychological well- being in the unemployed. Journal of employment counseling. 36, 67-81.

- Lyubomirsky, S., Sheldon, K. M., \& Schkade, D. (2005). Pursuing happiness: The architecture of sustainable change. Review of General Psychology, 9 (2), 111-131.

- Otake, K., Shimai, S., Tanaka-Matsumi, J., Otsui, K., \& Fredrickson, B. L. (2006). Happy people become happier through kindness: A counting kindnesses intervention. Journal of Happiness Studies, 7, 361 375.

- Peterson, C., \& Seligman, M.E.P. (2004).Character strengths and virtues: A classification and handbook. Washington, DC: American Psychological Association.

- Probst, M (2005). Economic Stressors. In J. Barlblication. Ing, E. Kelloway and M From (Eds,) Handbook of Work Stress. London: Sage Pu

- Seligman, M. E. P. (1991). Learned optimism: How to change your mind and your life. New York: Random House, Inc.

- Snyder, C.R., Irving, L., \& Anderson, J.R. (1991). Hope and Health: Measuring the will and the ways. In C.R. Snyder \& D.R. Forsyth (Eds.) Handbook of social and clinical psychology: The health perspective (pp.285-305). Elmsford, New York: Pergamon Press. Cited in Snyder, C.R. (2000). Hypothesis: There is Hope. In C.R. Snyder (Eds.), Handbook of Hope Theory, Measures and Applications (pp.3-21). San Diego: Academic Press.

- Wood, A., Froh, J., \& Geraghty, A. (2010). Gratitude and well-being: A review and theoretical integration. Clinical Psychology Review, 30, 890-905. 